San Jose State University

SJSU ScholarWorks

Master's Theses

Master's Theses and Graduate Research

1998

\title{
Ethnic differences in learning styles and study methods of college students
}

Sergio S. Queirolo

San Jose State University

Follow this and additional works at: https://scholarworks.sjsu.edu/etd_theses

\section{Recommended Citation}

Queirolo, Sergio S., "Ethnic differences in learning styles and study methods of college students" (1998). Master's Theses. 1666.

DOI: https://doi.org/10.31979/etd.k5zc-6tnm

https://scholarworks.sjsu.edu/etd_theses/1666

This Thesis is brought to you for free and open access by the Master's Theses and Graduate Research at SJSU ScholarWorks. It has been accepted for inclusion in Master's Theses by an authorized administrator of SJSU ScholarWorks. For more information, please contact scholarworks@sjsu.edu. 


\section{INFORMATION TO USERS}

This manuscript has been reproduced from the microfilm master. UMI films the text directly from the original or copy submitted. Thus, some thesis and dissertation copies are in typewriter face, while others may be from any type of computer printer.

The quality of this reproduction is dependent upon the quality of the copy submitted. Broken or indistinct print, colored or poor quality illustrations and photographs, print bleedthrough, substandard margins, and improper alignment can adversely affect reproduction.

In the unlikely event that the author did not send UMI a complete manuscript and there are missing pages, these will be noted. Also, if unauthorized copyright material had to be removed, a note will indicate the deletion.

Oversize materials (e.g., maps, drawings, charts) are reproduced by sectioning the original, beginning at the upper left-hand corner and continuing from left to right in equal sections with small overlaps. Each original is also photographed in one exposure and is included in reduced form at the back of the book.

Photographs included in the original manuscript have been reproduced xerographically in this copy. Higher quality 6" $\times 9$ " black and white photographic prints are available for any photographs or illustrations appearing in this copy for an additional charge. Contact UMI directly to order.

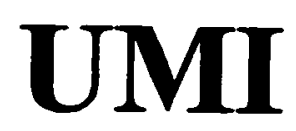

A Bell \& Howell Information Company

300 North Zeeb Road, Ann Arbor MI 48106-1346 USA

$313 / 761-4700 \quad 800 / 521-0600$ 


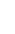




\title{
NOTE TO USERS
}

The original manuscript received by UMI contains pages with slanted print. Pages were microfilmed as received.

This reproduction is the best copy available

\author{
UMI
}




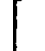

$\longrightarrow$ . . 


\title{
ETHNIC DIFFERENCES IN LEARNING STYLES AND STUDY METHODS OF COLLEGE STUDENTS
}

\author{
A Thesis \\ Presented to \\ the Faculty of the Department of Psychology \\ San Jose State University
}

In Partial Fulfillment

of the Requirements for the Degree

Master of Arts

by

Sergio S. Queirolo

May 1998 
UMI Number: 1389677

UMI Microform 1389677

Copyright 1998, by UMI Company. All rights reserved.

This microform edition is protected against unauthorized copying under Title 17, United States Code.

\section{UMI \\ 300 North Zeeb Road \\ Ann Arbor, MI 48103}


(C) 1998

Sergio Sean Queirolo

ALL RIGHTS RESERVED 


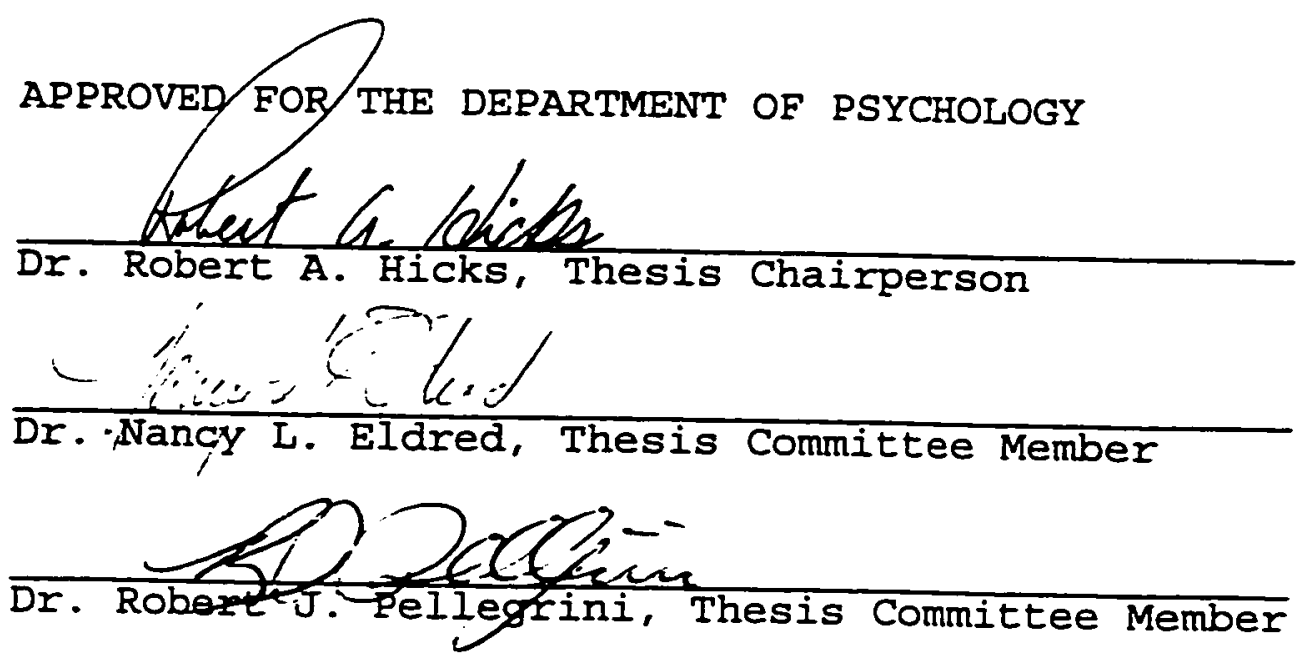

APPROVED FOR THE UNIVERSITY

William fisk 


\section{ABSTRACT \\ ETHNIC DIFFERENCES IN LEARNING STYLES AND \\ STUDY METHODS OF COLLEGE STUDENTS \\ by sergio s. Queirolo}

Ethnic minority students remain underrepresented in higher education settings, possibly due to lack of academic success during the first year of college (Cone \& Owens, 1991). While ethnic differences in children's learning styles have been reported (Dunn \& Griggs, 1990), more research is needed on the role ethnicity has on differences in academic success at the university level (Poodry, 1996). This study examines differences in the learning styles (measured by the Inventory of Learning Processes) and the study skills and behaviors (measured by the survey of study Habits and Attitudes) that are most related to the academic success of Caucasian, Mexican-American, and Vietnamese college students. Overall Grade Point Averages are used as measures of academic success. Practical and theoretical considerations are discussed. 


\section{ACKNOWLEDGMENTS}

This study could not have been completed without the support I received from Dr. Robert A. Hicks, Dr. Robert J. Pellegrini, and Dr. Nancy L. Eldred. Their insight proved enormously valuable and I thank them deeply for their membership on my Thesis Committee. I also extend my gratitude to Dr. Laree Huntsman, M.A. Program Coordinator, for the strength and support she has shared with students in the M.A. Program.

I am very grateful for the support I received from many fellow M.A. students. I am particularly indebted to Ruth Alfaro-Piker, Gina Liebig, Carol Mejia, and Jennifer Anthony. I would also like to acknowledge the boundless support I received from my relatives during the realization of this study.

This work was supported in part by a California state University 1996 Pre-Doctoral Summer Internship Grant. I am very grateful for having received the recognition and financial support from this grant. 
SECTION

PAGE

INTRODUCTION . • . . . . . . . . . . . . . . . . . . . 3

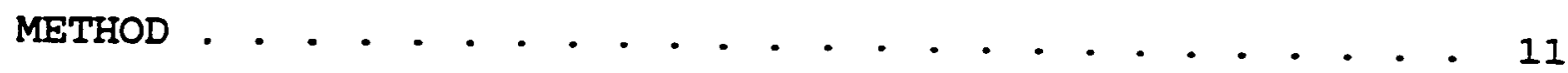

Research Participants . . . . . . . . . . . . . 11

Measures . . . . . . . . . . . . . . . . . 15

Procedure . . . . . . . . . . . . . . . . . . . 18

RESULTS AND PRELIMINARY DISCUSSION . • . • . . . . . . . 20

EXPLORATORY ANALYSES . • . • . • • . • . . . . . . . . . 24

Statistical Analyses and SES Evaluation . . . . . . 24

Analyses of SSHA Scales . . . . . . . . . . . . 24

Analyses of ILP Scales . . . . . . . . . . . . 31

Analyses of GPA . . . . . . . . . . . . . . . . 36

Summary of Exploratory Analyses . . . . . . . . . 39

CONCLUSIONS • . . . . . . . . . . . . . . . . . . . . . 41

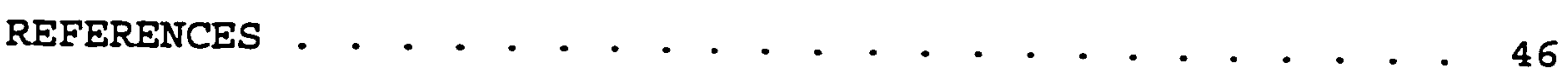

APPENDICES . . . . . . . . . . . . . . . . . . . . . . . . 49

Appendix A. Approval of Thesis Proposal and

Use of Human Subjects . . . . . . . 49

Appendix B. Sample Contact Letter . . . . . . . 52

Appendix C. Sample Research Sign-up Sheet . . . . 55

Appendix D. Background Questionnaire . . . . . . 57

Appendix E. Grade-Point-Average Release Form . . . 60

Appendix F. Informed Consent Form . . . . . . . . 61

Appendix G. Verification of Statistical

Assumptions and Analyses of

Socio-Economic Data . . . . . . . . . 64 


\section{LIST OF TABLES}

TABLE

PAGE

1. Number of Participants Majoring in Each of the University's Eight Colleges . . . . . . . . . . . . 14

2. Correlations Within SSHA Scales, and Between SSHA Scales and Overall GPA, for the Entire Sample and for Each Ethnic Group . . . . . . . . . 21

3. Correlations Within ILP Scales, and Between ILP Scales and Overall GPA, for the Entire Sample and for Each Ethnic Group . . . . . . . . . . . . 22

4. Descriptives for SSHA Scales, by Gender for Each Ethnic Group .

5. Multivariate Analyses of Variance with Ethnic Group and Gender for SSHA Scales . . . . . . . . . . 26

6. Descriptives for SSHA Scales, by Parents' Education Classification for Each Ethnic Group - . . 29

7. Multivariate Analyses of Variance with Ethnic Group and Parents' Education Classification for SSHA Scales . . . . . . . . . . . . . . . 30

8. Descriptives for ILP Scales, by Gender for Each Ethnic Group . . . . . . . . . . . . . . . . 32

9. Multivariate Analyses of Variance with Ethnic Group and Gender for ILP Scales

10. Descriptives for ILP Scales, by Parents' Education Classification for Each Ethnic Group . . . 35 
11. Multivariate Analyses of Variance with Ethnic Group and Parents' Education Classification for ILP Scales . . . . . . . . . . . . . . . . . 37

12. Descriptives for Overall GPA, by Gender for Each Ethnic Group . . . . . . . . . . . . . . . 38

13. Descriptives for Overall GPA, by Parents' Education Classification for Each Ethnic Group . . 40

G1. Tests of Homoscedasticity Across Ethnic Groups for Overall GPA and ILP and SSHA Scales . . . . . . 66

G2. Kolmogorov-Smirnov (Lilliefors) Normality Tests for Overall GPA and ILP and SSHA Scales . . . . . 67

G3. Number of Parents in Each Occupational Classification, for the Entire Sample and for Each Ethnic Group . . . . . . . . . . . . . . 69

G4. Number of Participants Whose Parents Fall in Each Income Quartile, for the Entire Sample and for Each Ethnic Group . . . . . . . . . . 70

G5. Number of Parents at Different Education Levels, for the Entire Sample and for Each Ethnic Group

G6. Number of Participants in Each Personal Income Quartile, for the Entire Sample and for Each Ethnic Group . . . . . . . . . . . . . . . . . . . 74

G7. Descriptives for Participants' Typical Number of Hours Worked Weekly and Personal Yearly Income, by Ethnic Group . . . . . . . . . . . 75 


\section{Ethnic Differences}

Ethnic Differences in Learning Styles and

Study Methods of College students

Sergio S. Queirolo

San Jose State University 
Abstract

Ethnic minority students remain underrepresented in higher education settings, possibly due to lack of academic success during the first year of college (Cone \& Owens, 1991). While ethnic differences in children's learning styles have been reported (Dunn \& Griggs, 1990), more research is needed on the role ethnicity has on differences in academic success at the university level (Poodry, 1996). This study examines differences in the learning styles (measured by the Inventory of Learning Processes) and the study skills and behaviors (measured by the Survey of Study Habits and Attitudes) that are most related to the academic success of Caucasian, Mexican-American, and Vietnamese college students. Overall Grade Point Averages are used as measures of academic success. Practical and theoretical considerations are discussed. 
Ethnic Differences in Learning Styles and Study Methods of College Students Introduction

For many years, U.S. educational institutions at the postsecondary level have devoted considerable resources to affirmative action programs with the goal of increasing the enrollment and academic success of ethnic minorities, and it is likely that these efforts contributed to the modest but steady increase of minority enrollment in higher education programs in science and engineering, where such enrollment increased from $17 \%$ in 1981 to $23 \%$ in 1993 (Wilson, 1995).

However, despite these signs of improvement, minority students continue to be underrepresented in higher education settings, perhaps because many of the existing strategies to increase the academic success of minorities were developed without a sound research foundation and may thus be meeting with only limited success (Poodry, 1996). Science education seems to be inadequate in preparing minorities for research careers, and in order to correct this deficiency that first emerges in elementary and middle school, more effective efforts seem needed to correct it during undergraduate and graduate training (Schneider, 1996).

To aid students who are at academic risk, about onehalf of all four-year state universities offer some type of college adjustment or study skills improvement course (Cone 
\& Owens, 1991), and at least some of these courses have been shown to increase students' academic attainment. For example, an investigation of the effectiveness of one such course that used sections of a commercially available program showed that 70 freshman students deemed at academic risk who enrolled in the course obtained higher Grade Point Averages (GPAs) than predicted at the end of the term, while the GPAs of 180 students also at risk but who did not participate in the course did not improve (Cone \& Owens).

Another researcher investigated the relationship between academic performance and general study techniques and attitudes toward college of 105 undergraduates enrolled in a reading improvement course at a southwestern university, and concluded that those students often engaged in ineffective study strategies (Turner, 1992).

Participants were given a 1300-word college-level passage on social stratification in America as the learning material, and later were administered a comprehension test that included recall, definition, inference, and conclusion questions to assess the students' literal and inferential understanding of the material. The investigator also administered the Survey of Study Habits and Attitudes (SSHA), which measures study methods, motivation for studying, and attitudes toward academic activities. Participants' ssHA scores indicated that the students had 
low scores in important areas such as promptness in completing academic assignments, opinions of teachers, and overall study habits and attitudes. The comprehension test was evaluated by comparing the students' responses to a protocol of responses found in the expository reading selection, and those answers matching the protocol were scored as correct. This evaluation indicated that most students correctly answered the recall (86\%) and definition ( $91 \%$ ) questions, but fewer students successfully answered inference questions (47\%), leading Turner to conclude that those students were not aware of, or were unable to use, effective study strategies resulting in higher levels of comprehension. Turner stated the need to help students develop and apply study behaviors appropriate for collegelevel coursework, emphasizing the importance of these behaviors for students' academic success.

Nist, Simpson, Olejnik, and Mealey (1991) examined the relationship between study processes and test performance. Participants of this study were 123 college freshmen whose university placement tests indicated they had difficulty comprehending and remembering lengthy expository text despite having intact reading skills. This investigation focused on four study processes: encoding (i.e., the cognitive processes of selecting, comprehending, storing, and retrieving information), word meaning (e.g., structural 
and contextual analyses that increase the comprehension of deeper aspects of text by focusing on the meaning instead of the recognition and pronunciation of words), organizing (e.g., concept cards, questions and answers, maps, charts, and essay prediction practice), and executive control (e.g., planning and defining tasks and goals, selecting the study strategies to be used, implementing and monitoring the selected study plan, and evaluating the plan's effectiveness after completion of the task). After an initial five-week training period, the investigators collected data on the participants' use of learning strategies dufing an additional five weeks. The students took multiple choice, true-false, and essay tests, and completed $\geqslant$ list of the learning strategies they had chosen to employ for each test. The analyses of this information revealed that executive control consistently had the highest correlations with test scores across the three tests (ranging from .40 to .47). All test scores were also statistically correlated with word-meaning scores, but these correlations were lower, ranging from .21 to .23. Regression analyses indicated that executive control was the best predictor of test performance, accounting for at least $20 \%$ of the variance.

This investigation by Nist, Simpson, olejnik, and Mealey (1991) suggested that some learning strategies are implicitly better than others, making it tempting to 
conclude that all freshman college students should increase their proficiency in executive control and word-meaning strategies to achieve higher grades. However, the population studied was composed almost exclusively of Caucasian students, and the results from this ethnically homogeneous sample may not apply to students of other ethnic backgrounds. If ethnic differences in learning style exist, strategies aimed at increasing the academic success of Caucasians may be less beneficial to minority students.

There is evidence suggesting that cultural or ethnic influences may lead students of different ethnic backgrounds to perform better academically using different learning styles. Dunn and Griggs (1990) examined and synthesized the results of eight investigations on the learning styles of children of different cultural or ethnic backgrounds. The authors noted that dropout high school students exhibit a learning style that is significantly different from the style employed by successful students. Dropouts are also more likely to be African-American, Hispanic, and AmericanIndian rather than Caucasian or Asian-American.

Dunn and Griggs (1990) found evidence of significant differences among students of diverse ethnic backgrounds in terms of the environmental stimulus most conducive to effective learning. For example, Chinese-Americans and Caucasians required sound while learning, whereas African- 
Americans required quiet while learning. African-Americans required significantly higher ambient temperature than Mexican-Americans and Chinese-Americans, while Caucasians preferred more warmth than Asians and Mexican-Americans. Chinese-Americans and Mexican-Americans required a formal design while studying, whereas African-Americans and Caucasians preferred an informal design.

In reviewing the eight studies, Dunn and Griggs (1990) also noted ethnic differences in other stimulus that were most amenable to effective learning. For example, AfricanAmericans were lower on the need for external structure (i.e., they preferred to work in their own way) than Caucasians, while African-American underachievers were more persistent than Caucasian underachievers. Important sociological differences were found also. For example, Mexican-Americans preferred learning alone more than African-Americans, while Caucasians were more peer-oriented than Mexican-Americans. Chinese-Americans and MexicanAmericans required significantly more variety than AfricanAmericans and Caucasians, while the latter groups required patterns and routines.

While some of the findings were not always compatible across the eight studies reviewed by Dunn and Griggs (1990), the investigators encountered consistent differences among the groups with respect to the learning styles the students 
preferred, and although some differences could be attributable to geographical or age differences, these studies suggest that significant ethnic differences exist in learning style. Thus, it seems worthwhile to investigate whether these differences play a role in academic performance at the college level.

Parenthetically, it should be noted that despite the availability of study-skills courses like the one described by Cone and Owens (1991), high-risk students often fail to seek out the help of such programs, possibly because these students may perceive themselves as incapable of academic excellence regardless of any help that might be available to them (Bliss \& Mueller, 1993). Thus, since affective factors such as perceived self-efficacy may play a role in the academic success of university students, it seems imperative that students at academic risk who participate in such study skills programs receive an effective intervention that capitalizes on their strengths rather than on a universal set of strategies that may not be of benefit to them.

In summary, a review of the literature reveals Iimited research on the role of ethnicity on differences in academic success at the university level (Nettles, 1990; Wilson, 1995), while minority students remain underrepresented on university campuses. This underrepresentation should be attributed to multiple and complex causes, one of which is 
lack of academic success during the first few years of college (Cone \& Owens, 1991). While there are many programs that enhance students' study skills and college success (Cone \& Owens), the ethnic differences in children's learning styles reported by Dunn and Griggs (1990) suggest the possibility that the strategies taught in such programs may be unequally effective for students of different ethnic or cultural backgrounds. Therefore, it seems important to determine whether there are ethnic differences in the learning styles and study skills and behaviors most related to academic success at the college level.

The goal of this study is to examine possible differences in the learning styles and study behaviors that are most correlated to the academic success of different ethnic groups, by assessing the relationships between the learning styles, study behaviors, and academic performance of Caucasian, Mexican-American, and Vietnamese college students. Learning styles are measured with the Inventory of Learning Processes (ILP), study behaviors are measured with the SSHA, and academic performance is measured with overall GPA.

Socio-economic disadvantage can impose limits on educational access (Steele, 1997) and may adversely affect psychological functioning and academic performance (National Advisory Mental Health Council, 1996), and there is 
substantial evidence of gender differences in cognitive abilities involving reading, writing, math, and science (Halpern, 1997). Thus, although socio-economic status (SES) and gender are not the focus of this study, a background questionnaire is included to assesses what impact (if any) SES and gender have on the relationships between ethnicity, ILP, SSHA, and GPA.

\section{Method}

\section{Research Participants}

Undergraduate, Iower-division San Jose State University students, 18 years old or older, of four ethnic backgrounds (African-American, Asian-American, Caucasian, and MexicanAmerican) and whose parents were of their same ethnic background (to maximize the ability of detecting cultural differences) were targeted for recruitment. To increase the number of participants of minority groups, contact letters (as shown in Appendix B) were mailed to 12 campus student organizations which were registered with the student Activities office and which identified one of this study's minority ethnic groups as a focus of the organization's interests. However, none of these organizations replied to the contact letter.

The remaining recruitment efforts focused on the pool of Introductory Psychology students, who were required to either participate in four hours of research or complete a 
written research assignment in order to receive a letter grade on their Introductory Psychology class. These students were targeted via sign-up sheets (shown in Appendix C), and during two "Open Research Day" sessions during which several researchers collected data for a variety of studies and Introductory Psychology students participated in the studies of their choice on a first-come, first-served basis. This semester-long data collection effort resulted in 138 students participating in this study.

The data from most of the 138 participants were excluded from analyses. Eleven participants indicated on their survey that they were Juniors or Seniors, and 21 others indicated that they were of Middle-Eastern, Canadian, Central-American, or South-American backgrounds, therefore these participants were excluded because they were not part of the target populations for this study. From the remaining 106 participants, the data from 12 participants who indicated their country of origin as China, 10 from the Philippines, 7 of African-American background, 5 from Korea, 4 from Japan, 3 from Taiwan, and 2 from Hong Kong, were excluded from the analyses because they did not compose large enough samples.

Only those participants who self-identified as being of Caucasian ( $\mathrm{n}=17$ ), Mexican-American ( $\mathrm{n}=17$ ), or Vietnamese $(n=29)$ backgrounds composed samples large enough to allow 
meaningful statistical comparisons. To increase homogeneity within the group of 29 participants who self-identified as being of Vietnamese origin, only the 17 who were born in Vietnam, whose parents were both born in Vietnam, and who had arrived at the U.S. at age 10 years or younger, remained in the sample. These restrictions were adopted to ensure that all participants had Iived in the U.S. for at least a few years, thus diminishing the potentially confounding effects of having English as a second language.

The 17 participants who self-identified as Caucasian reported that they and their parents were U.S.-born. The 17 participants who self-identified as Mexican-Americans reported being born in the U.S., with both parents born in Mexico, cr one parent born in the U.S. and the other in Mexico. All analyses for this study were conducted only with the data gathered from these 17 Caucasian (8 male, 9 female), 17 Mexican-American ( 6 male, 11 female), and 17 Vietnamese ( 6 male, 11 female) participants, whose ages ranged between 18 and 36 years, with a mean age of 20.0 years and a standard deviation of 3.5 years. As can be seen in Table 1, all Colleges except social work were represented in this sample.

All participants provided informed consent, and were treated in accordance with the "Ethical Principles of Psychologists and Code of Conduct" (American Psychological 
Table 1

Number of Participants Majoring in Each of the University's Eight Colleges

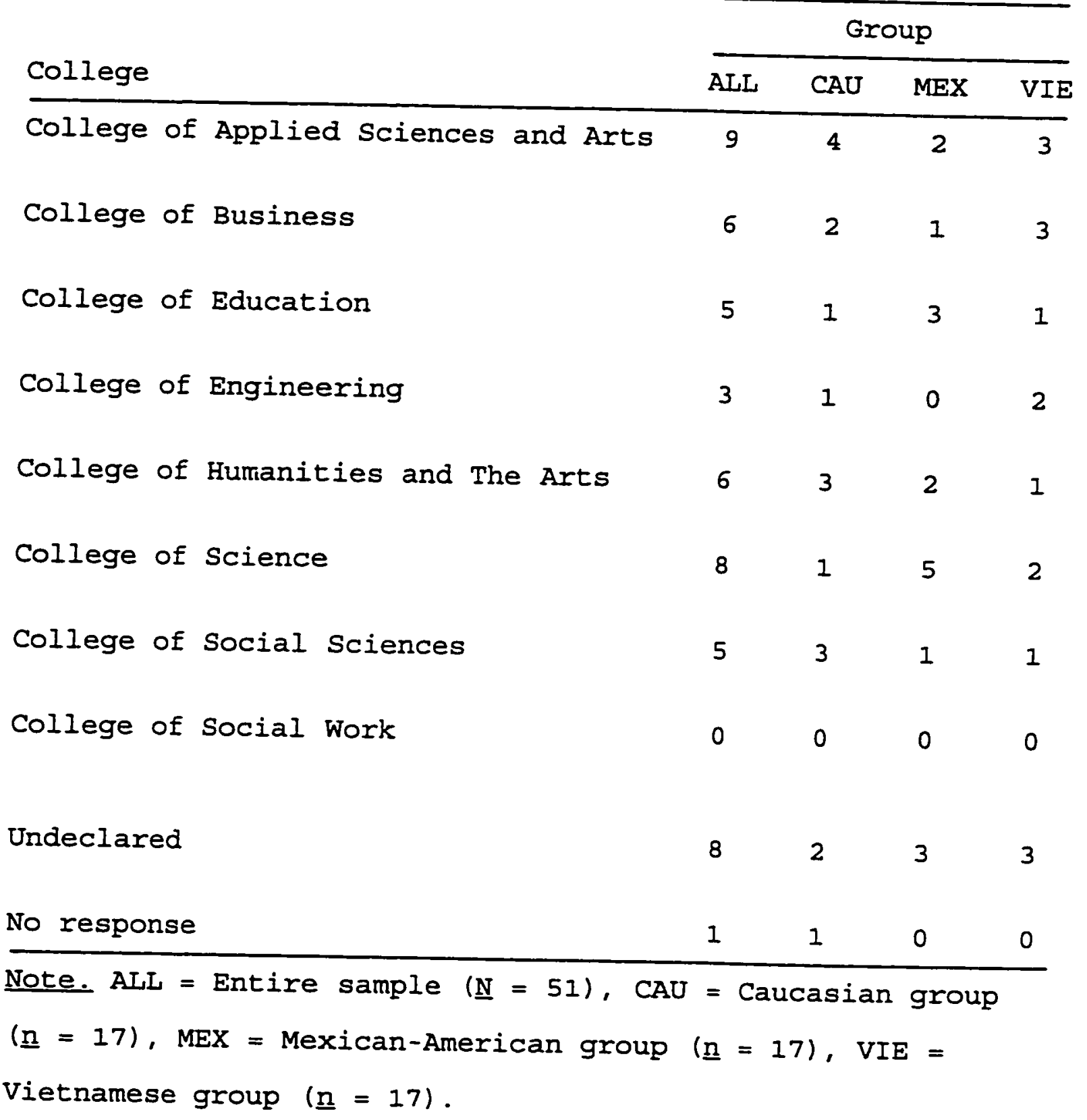


Association, 1992). All participants were enrolled in Introductory Psychology courses, and received a one-hour credit toward their four-hour experiment participation requirement even if their data was not included in the analyses. No other compensation was provided for participating in the study.

\section{Measures}

Survey of Study Habits and Attitudes. This scale was generated in 1955 by Brown \& Holtzman, who revised it in 1956 and 1965. The 1965 version of this survey consists of 100 multiple-response items that measure attitudes toward scholastic activities, motivation for studying, and study methods. The SSHA is comprised of four 25-item scales that assess Delay Avoidance (DA), Work Methods (WM), Teacher Approval (TA), and Education Acceptance (EA).

The DA scale assesses promptness in completing assignments and ability to resist distractions. The WM scale evaluates study procedures, skill, and efficiency in doing academic assignments. The TA scale appraises students' feelings and opinions about teachers and their classroom behaviors and methods. The EA scale consists of items that measure students' approval of educational objectives, practices, and requirements.

The SSHA Manual (Brown \& Holtzman, 1965) provides the following data on the psychometric properties of the SSHA. 
Internal consistencies for the four main SSHA scales were assessed with a sample of 465 college freshmen and were measured at .89 for $\mathrm{DA}, .87$ for $\mathrm{WM}, .87$ for $\mathrm{TA}$, and .89 for EA. Test-retest reliability over a four-week period with a sample of 144 college freshmen was .93 for DA, .91 for WM, .88 for TA, and .90 for EA. The reliability over a 14-week interval for a sample of 51 college freshmen was measured at .88 for $D A, .86$ for WM, .83 for $T A$, and .85 for $E A$.

From a sample of 1772 college freshmen, correlations of the four main SSHA scores with semester GPA and scholastic aptitude test scores were measured at .31 and .08 for DA, .32 and .30 for WM, .25 and .16 for $T A$, and .35 and .14 for EA, respectively. These correlations suggest that while the four SSHA scales measure traits that play an important role in academic achievement, only the WM scale is appreciably related to scholastic aptitude as measured by ACEPE, SCAT, or CEEB-SAT scores.

Inventory of Learning Processes. This survey was originally developed by Schmeck, Ribich, and Ramanaiah in 1977, and revised by Schmeck in 1983. The 1983 version of the inventory consists of 62 true-false items that appraise different learning behaviors that college students are likely to utilize. The survey items are grouped into four scales: Deep Processing (DP), Methodical study (MS), Elaborative Processing (EP), and Fact Retention (FR). 
The DP scale consists of 18 items that assess the extent to which students critically evaluate, conceptually organize, and compare and contrast the information they study. An internal consistency of .82 and a test-retest reliability of .88 over a two-week period are reported for this scale (Schmeck, 1983).

The MS scale is composed of 23 items that tap into methods that students use for studying, such as frequency and orderliness of studying, with an internal consistency of .74 and a test-retest reliability of .83 (Schmeck, 1983).

The EP scale consists of 14 items that measure the extent to which a person makes new information personally relevant and uses visual imagery to encode new ideas, with an internal consistency of .67 , and a test-retest reliability of .80 (Schmeck, 1983).

The FR scale, with seven items, measures how carefully individuals store and process details and specific pieces of new information, with an internal consistency of .58 and a test-retest reliability of .79 (Schmeck, 1983).

Background Questionnaire. To foster meaningful comparisons between the ethnic groups studied, as well as to facilitate any future meta-analyses that might be conducted, gender and descriptive SES information was obtained from each participant via a background questionnaire which is presented in Appendix D. Because it was not possible to 
ensure, prior to collecting data, that the participants' sEs was similar across the three groups, it was deemed necessary to attempt to account for (and remove) any variance due to differences in gender or SES during analyses. The effect of SES was operationalized as the variance attributable to the participants' marital status, personal yearly income, weekly work-hours, and their parents' education level, occupation, and yearly income.

Parents' education level was categorized according to the highest level of education completed (i.e., none, elementary school, middle school, high school, trade school or some college, and college). Parental occupation was coded using the Dictionary of Occupational Titles (U.S. Employment Service, 1991) and placed participants' parents in one of eight occupational clusters (i.e., professional/ technical/managerial, clerical/sales, service, agricultural/ fishery/forestry, processing, machine trades, benchwork, and miscellaneous occupations).

Grade Point Average. Participants' overall GPAs were obtained from the University's Admissions and Records Office via a form shown in Appendix E. Overall GPA was employed as a measure of each participant's academic success.

\section{Procedure}

One-hour sessions were scheduled throughout the academic semester in different classrooms around campus. At 
the beginning of each session, the investigator greeted all participants and briefly described the study as "an investigation on the study habits and learning styles of students of different ethnic groups, looking at possible different correlations between different study and learning methods, and grade point average." The investigator then distributed to each participant two copies of an informed consent form (shown in Appendix F), a release form to obtain official GPAs from the Office of Admissions and Records, and the Background, ILP, and SSHA questionnaires.

Participants were asked to read the consent form, and upon deciding to participate, sign two copies and keep one for their records, and were informed that they could return all materials to the investigator and leave the room quietly should they decide not to participate or terminate their participation at any time. They were asked to answer every item on the questionnaires as honestly and accurately as possible, making sure that each answer reflected how each item applied to them in real life, instead of choosing what they thought was the ideal answer for each item. Only one student (an African-American female) decided to terminate her participation after reviewing the questionnaires, and the researcher thanked her for her time and shredded and discarded her partially completed survey at the end of that session. When each participant completed all of his or her 
questionnaires, he or she returned the materials to the investigator, who then signed the participant's research participation form. The student was thanked and dismissed.

Results and Preliminary Discussion

As a first step in investigating the relationships between participants' ethnic classification, learning styles, study behaviors, and academic performance, correlations were calculated within SSHA scales, and between SSHA scales and overall GPA (as shown in Table 2), as well as within ILP scales, and between ILP scales and overall GPA (as shown in Table 3), for each ethnic group. These analyses revealed that the SSHA and ILP scales were not equally predictive of GPA for the different groups. None of the scales were significantly correlated to the overall GPA of students in the Vietnamese or Mexican-American groups, while only the FR scale did not correlate significantly with the GPA of students in the Caucasian group.

These findings could suggest that the ILP and SSHA scales may not effectively measure learning processes and behaviors related to the academic performance of MexicanAmerican and Vietnamese college students, and consequently these students may profit academically the most from study methods and learning processes with underlying structures different from those that are measured by these scales. Conversely, it could be theorized that participants in the 
Table 2

Correlations within SSHA Scales, and Between SSHA Scales and Overall GPA, for the Entire Sample and for Each Ethnic Group

SSHA Work Teacher Education Total

\begin{tabular}{lccccc} 
Scale & Group & Methods & Approval & Acceptance & GPA \\
\hline Delay & ALL & $.703 \star \star$ & $.500 \star \star$ & $.755 \star \star$ & $.326 \star$
\end{tabular}

Avoidance

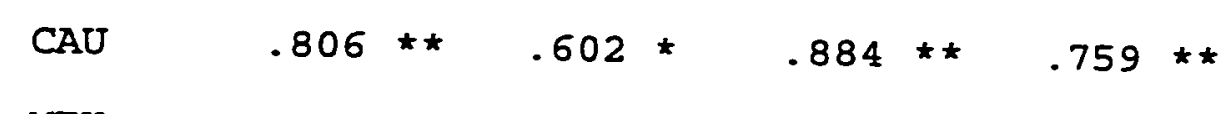

Work

MEX $\quad .403 \quad .217 \quad .560 * \quad .036$

Methods

VIE .719

**

$.676 \star \star$

$.737 * \star \quad .040$

ALI

$.752 \star \star \quad .237$

Methods

CAU

MEX

$.797 \star \star .738$

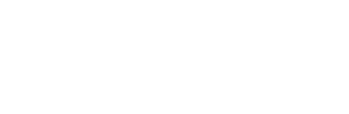

Teacher

Approval

VIE

$.636 \star \star \quad .680 * \star \quad .133$

AII

$.622 \star \star \quad .708 * \star \quad-.036$

ALL

$.821 \star \star-.016$

CAU

$.759 \star \star .529 *$

MEX

$.812 \star \star-.186$

VIE

$.860 * *-.043$

Education

ALL

.188

Acceptance

CAU

.744

MEX

$-.014$

VIE

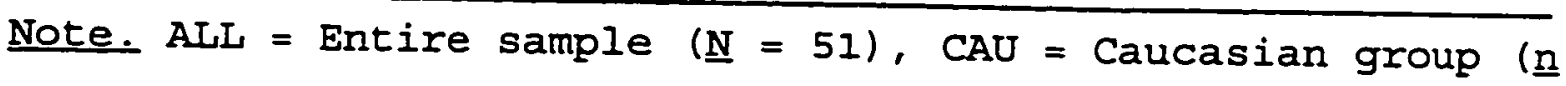
=17), $\mathrm{MEX}=$ Mexican-American group ( $\underline{\underline{n}}=17), \mathrm{VIE}=$ Vietnamese group $(\underline{\mathrm{n}}=17)$.

$\star \mathrm{p}<.05 . \quad \star * \mathrm{p}<.01$. 
Table 3

Correlations Within ILP Scales, and Between ILP Scales and Overall GPA, for the Entire Sample and for Each Ethnic Group

\begin{tabular}{|c|c|c|c|c|c|c|c|}
\hline ILP & \multirow[b]{2}{*}{ Group } & Methodical & \multicolumn{2}{|l|}{ Fact } & \multicolumn{2}{|c|}{ Elaborative } & \multirow{2}{*}{$\begin{array}{c}\text { Total } \\
\text { GPA }\end{array}$} \\
\hline Scale & & Study & Retentio & on & Process & sing & \\
\hline Deep & ALL & $.290 \star$ & $.516 \star$ & $\star \star$ & $.477 \star$ & $\star \star$ & .064 \\
\hline Processing & $C A U$ & .461 & $.518 \star$ & * & .106 & & $.601 *$ \\
\hline & MEX & .252 & .405 & & $.530 \star$ & * & .081 \\
\hline & VIE & .418 & $.756 \star$ & $\star \star$ & $.588 *$ & * & -.160 \\
\hline Methodical & $A L L$ & & .225 & & $.500 *$ & $\star \star$ & .258 \\
\hline Study & CAU & & .073 & & $.513 *$ & * & $.818 *$ \\
\hline & MEX & & .121 & & .423 & & .008 \\
\hline & VIE & & $.519 *$ & * & $.631 \times$ & $\star \star$ & -.073 \\
\hline Fact & ALI & & & & $.369 x$ & $\star \star$ & .116 \\
\hline Retention & CAU & & & & -.054 & & .178 \\
\hline & MEX & & & & .417 & & .340 \\
\hline & VIE & & & & .657 & $\star \star$ & -.094 \\
\hline Elaborative & ALL & & & & & & .097 \\
\hline Processing & CAU & & & & & & $.534 \star$ \\
\hline & MEX & & & & & & .202 \\
\hline & VIE & & & & & & -.178 \\
\hline
\end{tabular}

Note. ALL = Entire sample $(\underline{\underline{N}}=51)$, CAU = Caucasian group $(\underline{n}$ =17), $\operatorname{MEX}=$ Mexican-American group $(\underline{\underline{n}}=17), \mathrm{VIE}=$ Vietnamese group ( $\underline{n}=17)$.

$\star \underline{p}<.05 . \star \star \mathrm{D}<.01$. 
Mexican-American and Vietnamese groups were not effectively engaging in the behaviors they endorsed in the SSHA and ILP measures.

This difference in predictive ability brings up important issues for the administration of higher education programs. To the extent that the findings of this study reflect differences present in the population, they encourage the performance of similar analyses on other measures that may be used to predict academic performance (e.g., for admissions' selection purposes), since such tools may not be appropriately measuring the academic potential of students of different ethnic groups.

This study originally aimed at exploring possible differences in the learning styles and study behaviors that are most correlated to the academic success of students with different ethnic backgrounds, but the lack of significant correlations between ILP, SSHA, and GPA in two of the groups interferes with this assessment, since these scales did not prove useful in identifying learning styles or study behaviors related to the academic success of MexicanAmerican or Vietnamese students.

Upon examination of this finding, it was decided to carry out exploratory analyses, to determine whether the three groups differed in the learning processes and study behaviors they engaged in (regardless of their correlation 
to participants' academic performance), and whether the groups differed in overall GPA.

Exploratory Analyses

Statistical Assumptions and SES Evaluation

Prior to determining the significance of possible ethnic group differences in GPA, ILP, and SSHA, these data were inspected to assess their fulfillment of statistical properties required for valid interpretation of Analyses of Variance (ANOVA) results. In addition, SES variables were analyzed to determine which ones would be included in the ANOVA analyses of GPA, SSHA, and IIP.

As a result of these analyses, detailed in Appendix G, it was decided to carry out ANOVAs on all SSHA and ILP scales, as well as on GPA. It was also decided to include participants' gender, as well as their parents' educational classification, in the exploratory ANOVA analyses, to measure their contribution to any ethnic differences in SSHA, ILP, and GPA. The results of these analyses are described next.

\section{Analyses of SSHA Scales}

As shown in Table 4, means and standard deviations were obtained for the SSHA scales, by gender and ethnic group. Results of ANOVA analyses of the SSHA scales, summarized in Table 5, revealed significant ethnic group and gender differences for each SSHA scale. Females consistently 
Table 4

Descriptives for SSHA Scales, by Gender for Each Ethnic Group

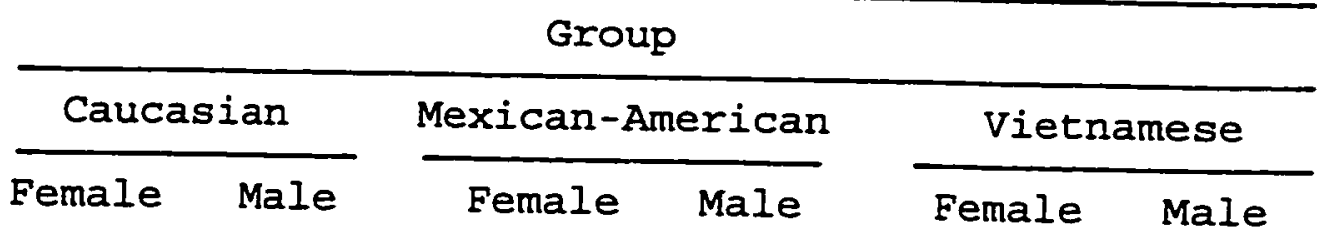

\begin{tabular}{cccccccc} 
Scale & $(\underline{\underline{n}}=9)$ & $(\underline{\underline{n}}=8)$ & $(\underline{\underline{n}}=11)$ & $(\underline{\underline{n}}=6)$ & $(\underline{\underline{n}}=13)$ & $(\underline{\underline{n}}=6)$ \\
\hline DA & $\underline{M}$ & 26.78 & 15.00 & 18.27 & 10.33 & 17.18 & 8.67 \\
& $\underline{\text { SD }}$ & 9.98 & 10.18 & 6.69 & 5.20 & 9.01 & 2.50
\end{tabular}

WM

$\begin{array}{lrrrrrr}\text { M } & 30.67 & 23.88 & 23.09 & 14.83 & 17.91 & 13.00 \\ \text { SD } & 8.17 & 10.09 & 9.32 & 6.37 & 8.56 & 6.93\end{array}$

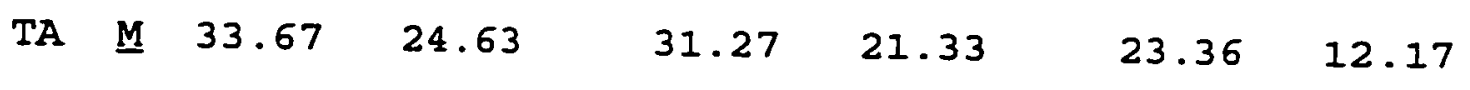

$\begin{array}{lllllll}\text { SD } & 7.33 & 8.21 & 12.05 & 12.69 & 7.53 & 9.45\end{array}$

$\begin{array}{llllllll}E A & M & 30.00 & 20.25 & 26.91 & 17.17 & 20.09 & 13.50\end{array}$

\begin{tabular}{lllllll} 
SD & 7.65 & 8.88 & 7.98 & 5.27 & 9.15 & 7.82 \\
\hline
\end{tabular}

Note. $D A=$ Delay Avoidance, $W M=$ Work Methods, $T A=$ Teacher Approval, $E A=$ Education Acceptance. 
Table 5

Multivariate Analyses of Variance with Ethnic Group and Gender for SSHA Scales

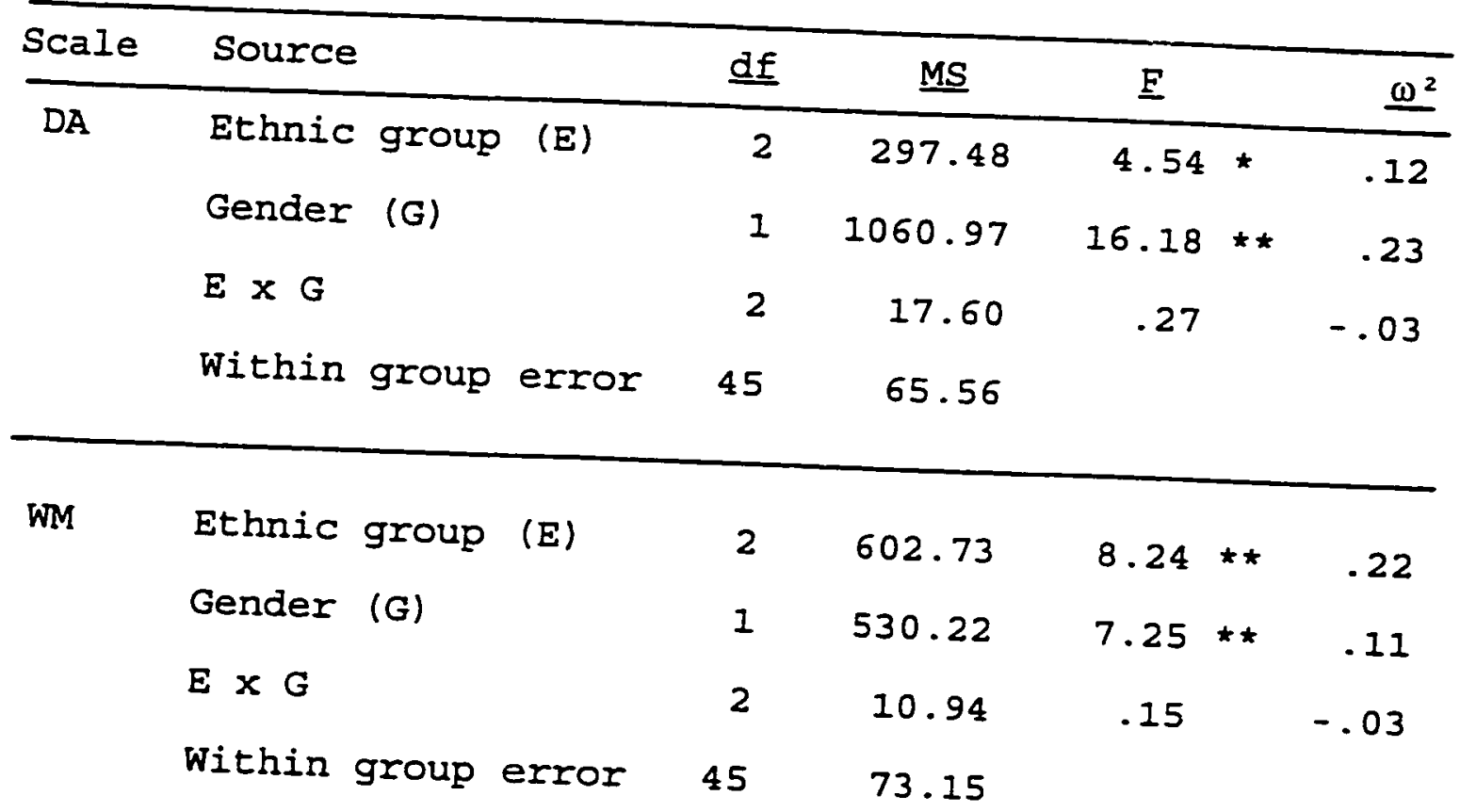

TA

$\begin{array}{lrrrr}\text { Ethnic group (E) } & 2 & 560.22 & 6.04 * \star & .17 \\ \text { Gender (G) } & 1 & 1212.24 & 13.07 * \star & .19 \\ \text { Ex G } & 2 & 4.73 & .05 & -.04 \\ \text { Within group error } & 45 & 92.73 & & \end{array}$

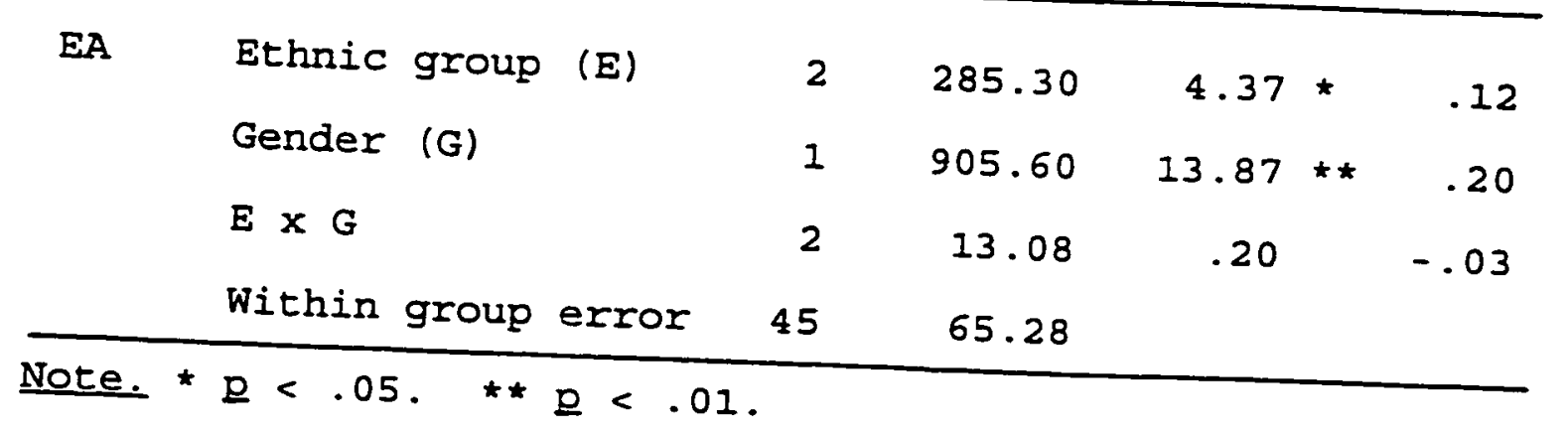


scored significantly higher than males on all four SSHA scales, but no ethnicity by gender interactions were detected.

Main comparisons revealed that participants in the Caucasian group scored higher on the DA scale than those in the Mexican-American $[\underline{F}(1,45)=4.31, \underline{D}<.05]$ and the Vietnamese $[\underline{F}(1,45)=6.46, \underline{p}<.05]$ groups, but participants in the Mexican-American and Vietnamese groups did not score differently on this scale $[\underline{F}(1,45)=.22$, n.s.]. Similarly, those in the Caucasian group obtained a higher score on the WM scale than their peers in the Mexican-American $[\underline{E}(1,45)=6.18, \underline{\underline{p}}<.05]$ and the Vietnamese $[\underline{F}(1,45)=14.82, \underline{D}<01]$ groups, while participants in the Mexican-American and Vietnamese groups did not score differently on this scale $[\underline{E}(1,45)=1.86$, n.s.].

Analyses of the TA and EA scales revealed a different pattern. Students in the Caucasian and Mexican-American groups did not score differently on the $\mathrm{TA}$ scale $[\underline{F}(1,45)=$ .25, n.s.], while those in the Vietnamese group scored significantly lower than their peers in the caucasian [E( 1 , $45)=9.17, \underline{p}<.01]$ and the Mexican-American $[\underline{F}(1,45)=$ $6.40, \underline{\mathrm{p}}<.05]$ groups on this measure. Similarly, on the EA scale, the mean scores of participants in the Caucasian and Mexican-American groups were not significantly different 
$[E(1,45)=.49$, n.s.], while the mean EA score for those in the Vietnamese group was significantly lower than the score of their peers in the Caucasian $[\underline{F}(1,45)=7.61, \underline{D}<.01]$ and the Mexican-American $[\underline{F}(1,45)=4.24, \underline{p}<.05]$ groups. Means and standard deviations were computed for the SSHA scales, by ethnic group and parents' education level (as shown in Table 6), and ANOVAs were performed to determine whether participants' ethnic background and parents' education classification contributed to variance of SSHA scores. As summarized in Table 7, significant differences were detected between the scores obtained by participants in the three ethnic groups across all SSHA scales. Additionally, scores in the DA and EA scales were significantly lower for participants having at least one parent who attained an education beyond high school, but detected no ethnic group by parents' education interactions.

Main comparisons on the DA scale revealed that participants in the Caucasian group scored higher than their peers in the Vietnamese group $[\underline{F}(1,45)=5.28, \underline{p}<.05]$ but not differently than those in the Mexican-American group $[E(1,45)=3.52$, n.s.], while participants in the MexicanAmerican and Vietnamese groups did not score differently on this scale $[\underline{F}(1,45)=.18$, n.s. $]$.

Main comparisons on the WM scale revealed that participants in the Caucasian group scored higher than their 
Table 6

Descriptives for SSHA Scales, by Parents' Education

Classification for Each Ethnic Group

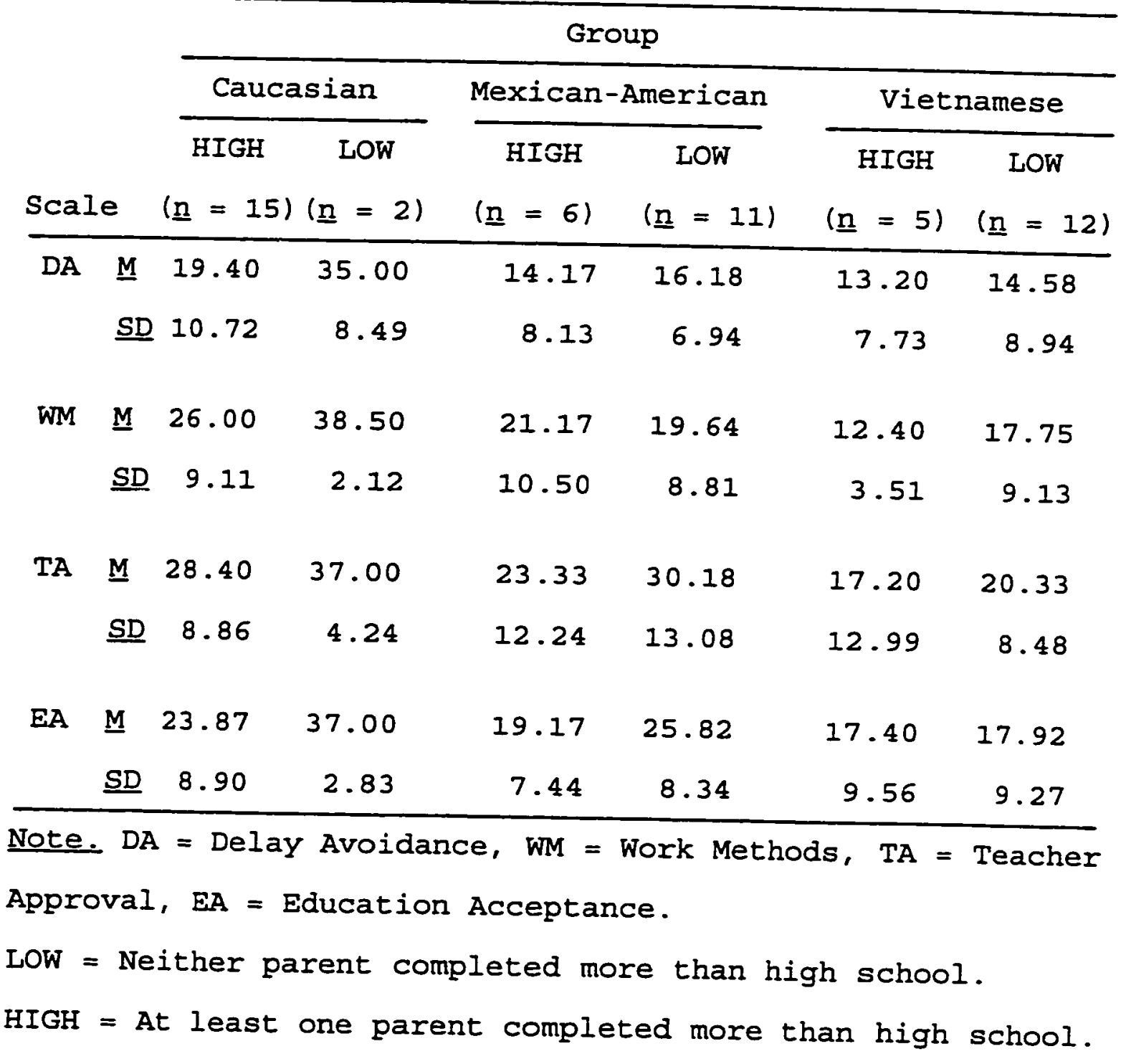


Table 7

Multivariate Analyses of Variance with Ethnic Group and Parents' Education Classification for SSHA Scales

\begin{tabular}{|c|c|c|c|c|c|c|}
\hline Scale & Source & $\underline{d f}$ & $\underline{\mathrm{MS}}$ & $\underline{E}$ & & $\underline{\omega}^{2}$ \\
\hline \multirow[t]{4}{*}{$\mathrm{DA}$} & Ethnic group (E) & 2 & 461.28 & 5.75 & $\star \star$ & .16 \\
\hline & Parents' Education (P) & $I$ & 325.89 & 4.06 & $\star$ & .06 \\
\hline & $E \times P$ & 2 & 137.78 & 1.72 & & .03 \\
\hline & Within group error & 45 & 80.26 & & & \\
\hline \multirow[t]{4}{*}{ WM } & Ethnic group (E) & 2 & 694.78 & 9.04 & $\star \star$ & .24 \\
\hline & Parents' Education (P) & 1 & 240.46 & 3.13 & & .04 \\
\hline & $E \times P$ & 2 & 126.18 & 1.64 & & .02 \\
\hline & within group error & 45 & 76.87 & & & \\
\hline \multirow[t]{4}{*}{$T A$} & Ethnic group (E) & 2 & 506.96 & 4.52 & $\star$ & .12 \\
\hline & Parents' Education (P) & 1 & 311.75 & 2.78 & & .03 \\
\hline & $E \times P$ & 2 & 21.59 & .19 & & -.03 \\
\hline & Within group error & 45 & 112.05 & & & \\
\hline \multirow[t]{4}{*}{$E A$} & Ethnic group (E) & 2 & 385.49 & 5.10 & $\star$ & .14 \\
\hline & Parents' Education (P) & 1 & 372.12 & 4.92 & * & .07 \\
\hline & $E \times P$ & 2 & 97.80 & 1.29 & & .01 \\
\hline & Within group error & 45 & 75.56 & & & \\
\hline
\end{tabular}

Note. $* \mathrm{p}<.05 . \star \star \star \mathrm{p}<.01$.

The categorical Parents' Educarion variable dichotomized participants on whether or not at least one of their parents completed an educational objective beyond high school. 
peers in the Mexican-American $[\underline{F}(1,45)=5.88, \underline{D}<.05]$ and Vietnamese $[E(1,45)=14.10, \underline{p}<.01]$ groups, but students in the Mexican-American and Vietnamese groups did not score differently on this scale $[\underline{F}(1,45)=1.77$, n.s.].

Main comparisons on the TA scale revealed that participants in the Caucasian group scored significantly higher than their peers in the Vietnamese group $[\underline{F}(1,45)=$ 7.59, $\mathrm{D}<.01$ ] but not differently than those in the Mexican-American group $[\underline{E}(1,45)=.21$, n.s.], while participants in the Mexican-American group scored higher on this scale than those in the vietnamese group $[\underline{F}(1,45)=$ $5.29, \underline{\text { }}<.05]$.

Main comparisons on the EA scale revealed that participants in the Caucasian group scored significantly higher than their peers in the vietnamese group $[\underline{F}(1,45)=$ $6.58, \underline{p}<.05$ ] but not differently than those in the Mexican-American group $[\underline{F}(1,45)=.42$, n.s.]. Participants in the Mexican-American and Vietnamese groups did not obtain significantly different scores on this scale $[\underline{F}(1,45)=$ $3.66, \mathrm{n} . \mathrm{s} . \mathrm{l}$.

\section{Analyses of ILP scales}

Means and standard deviations were computed for each ILP scale, by gender and ethnic group (as shown in Table 8). The ANOVAs performed on the ILP scales, summarized in Table 9. indicate that there were no significant differences 
Table 8

Descriptives for ILP Scales, by Gender for Each Ethnic Group

$\frac{\text { Group }}{\text { Female Male }} \frac{\text { Mexican-American }}{\text { Female Male }} \quad \frac{\text { Vietnamese }}{\text { Female Male }}$

\begin{tabular}{|c|c|c|c|c|c|c|c|}
\hline \multicolumn{2}{|c|}{ Scale } & $(\underline{\underline{n}}=9)$ & $(\underline{n}=8)$ & $(\underline{n}=11)$ & $(\underline{n}=6)$ & $(\underline{n}=13)$ & $(\underline{\underline{n}}=6)$ \\
\hline \multirow[t]{2}{*}{$\mathrm{DP}$} & $\underline{\mathrm{M}}$ & 13.11 & 13.75 & 10.82 & 8.67 & 6.91 & 7.00 \\
\hline & $\underline{S D}$ & 3.48 & 3.06 & 4.56 & 4.18 & 4.01 & 4.15 \\
\hline \multirow[t]{2}{*}{ MS } & $\underline{\mathbf{M}}$ & 11.67 & 6.75 & 10.18 & 7.50 & 11.64 & 5.50 \\
\hline & $\underline{\text { SD }}$ & 5.92 & 3.77 & 5.38 & 6.98 & 4.90 & 3.02 \\
\hline \multirow[t]{2}{*}{ FR } & $\underline{\mathbf{M}}$ & 3.89 & 5.50 & 4.09 & 4.83 & 4.55 & 3.33 \\
\hline & $\underline{S D}$ & 2.03 & 1.41 & 1.97 & 1.47 & 1.63 & 2.07 \\
\hline \multirow[t]{2}{*}{ EP } & $\underline{\mathrm{M}}$ & 9.89 & 9.25 & 9.36 & 9.33 & 8.63 & 6.67 \\
\hline & $\underline{S D}$ & 2.57 & 3.06 & 3.20 & 1.86 & 3.01 & 3.93 \\
\hline
\end{tabular}

Note. $D P=$ Deep Processing, $M S=$ Methodical Study, $F R=$ Fact Retention, $\mathrm{EP}=$ Elaborative Processing. 
Table 9

Multivariate Analyses of Variance with Ethnic Group and Gender for ILP Scales

\begin{tabular}{|c|c|c|c|c|c|c|}
\hline Scale & Source & $\underline{\mathrm{df}}$ & $\underline{\mathrm{MS}}$ & $\underline{E}$ & & $\underline{\omega^{2}}$ \\
\hline \multirow[t]{4}{*}{$\mathrm{DP}$} & Ethnic group (E) & 2 & 171.73 & $10.97 *$ & $\star \star$ & .28 \\
\hline & Gender $(G)$ & 1 & 2.69 & .17 & & -.02 \\
\hline & $E \times G$ & 2 & 8.70 & .56 & & -.02 \\
\hline & Within group error & 45 & 15.65 & & & \\
\hline \multirow[t]{4}{*}{ MS } & Ethnic group (E) & 2 & 1.68 & .06 & & -.04 \\
\hline & Gender (G) & 1 & 251.11 & $9.43 \times$ & ** & .14 \\
\hline & $E \times G$ & 2 & 11.94 & .45 & & -.02 \\
\hline & Within group error & 45 & 26.64 & & & \\
\hline \multirow[t]{4}{*}{ FR } & Ethnic group (E) & 2 & 2.40 & .75 & & -.01 \\
\hline & Gender (G) & 1 & 1.73 & .54 & & -.01 \\
\hline & $E \times G$ & 2 & 8.38 & 2.61 & & .06 \\
\hline & Within group error & 45 & 3.22 & & & \\
\hline \multirow[t]{4}{*}{ EP } & Ethnic group (E) & 2 & 17.45 & 1.93 & & .04 \\
\hline & Gender (G) & 1 & 9.27 & 1.03 & & .00 \\
\hline & $E \times G$ & 2 & 3.83 & .42 & & -.02 \\
\hline & Within group error & 45 & 9.03 & & & \\
\hline
\end{tabular}


between the scores obtained by the two gender groups for the $D P, F R$, and EP scales, but females scored significantly higher than males on the MS scale. The ANOVAs also revealed that participants in the three ethnic groups obtained similar scores on the MS, FR, and EP scales, but did not score similarly on the DP scale.

In order to locate the source of this difference between the three ethnic groups, main comparisons were performed, revealing that participants in the Caucasian group scored significantly higher on the DP scale than their peers in both the Mexican-American $[\underline{F}(1,45)=6.11, \underline{p}<$ $.05]$ and the vietnamese $[\underline{E}(1,45)=22.74, \underline{p}<.01]$ groups, while those in the Mexican-American group scored significantly higher than participants in the Vietnamese group $[\underline{F}(1,45)=5.28, \underline{p}<.05]$ on this scale. There were no significant interactions between ethnic group and gender for any ILP scale.

Means and standard deviations were computed for the ILP scales, by ethnic group and parents' education level (as shown in Table 10). The corresponding ANOVAs performed on the ILP scales revealed no significant differences in the scores for the DP, FR, and EP scales between the two groups defined by parents' education classification, while scores in the MS scaie were lower for those participants having at least one parent who attained an education beyond high 
Table 10

Descriptives for ILP Scales, by Parents' Education

Classification for Each Ethnic Group

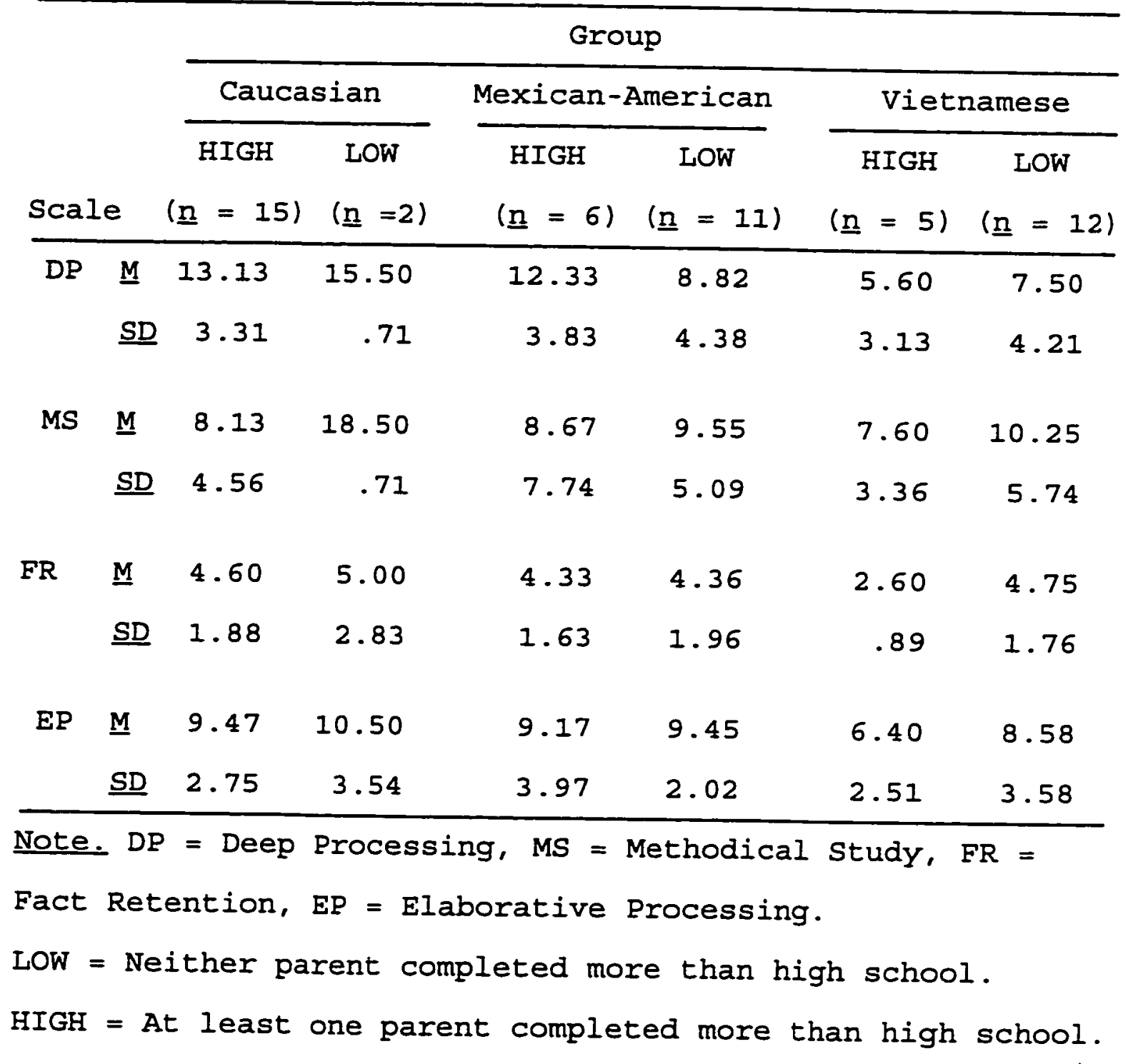


school. As can be seen in Table 11, no significant interactions were detected between ethnic group and parents' education classification, and no differences were detected between the scores obtained by participants in the three ethnic groups on the MS, FR, and EP scales.

However, participants' scores were significantly different on the DP scale. Main comparisons on this scale revealed that Caucasian participants scored significantly higher than their Mexican-American $[\underline{E}(1,45)=6.58, \underline{\mathrm{D}}<$ $.05]$ and Vietnamese $[\underline{E}(1,45)=24.51, \underline{D}<.01]$ peers, while those in the Mexican-American group scored higher than their peers in the Vietnamese group $[\underline{E}(1,45)=5.69, \underline{\underline{q}}<.05]$. Analyses of GPA

Descriptives on GPA, presented in Table 12, reveal that participants in the Mexican-American group earned a mean overall GPA of "C+", while their peers in the Caucasian group earned a "B-" and those in the Vietnamese group earned a stronger "B-". An ANOVA revealed that the ethnic groups were significantly different on overall $\operatorname{GPA}[\underline{F}(2,45)=$ $\left.3.28, \underline{\mathrm{L}}<.05, \underline{\omega^{2}}=.08\right]$, but gender did not contribute significantly to this variance $[\underline{F}(1,45)=.16, \mathrm{n} . \mathrm{s}$.$] , and$ there was no significant ethnic group by gender interaction $[\underline{E}(2,45)=1.35$, n.S. $]$.

Main comparisons revealed that the mean overall GPA obtained by participants in the Caucasian group was not 
Table 11

Multivariate Analyses of Variance with Ethnic Group and Parents' Education Classification for ILP Scales

\begin{tabular}{|c|c|c|c|c|c|}
\hline Scale & Source & $\underline{\mathrm{df}}$ & $\underline{\text { MS }}$ & $\underline{E}$ & $\underline{\omega}^{2}$ \\
\hline \multirow[t]{4}{*}{$\mathrm{DP}$} & Ethnic group (E) & 2 & 151.18 & 10.41 & .27 \\
\hline & Parents' Education (P) & 1 & .51 & .04 & -.02 \\
\hline & $E \times P$ & 2 & 34.88 & 2.40 & .05 \\
\hline & Within group error & 45 & 14.52 & & \\
\hline \multirow[t]{4}{*}{ MS } & Ethnic group (E) & 2 & 52.75 & 1.89 & .03 \\
\hline & Parents' Education (P) & 1 & 174.33 & 6.24 & .09 \\
\hline & $E \times P$ & 2 & 56.16 & 2.01 & .04 \\
\hline & within group error & 45 & 27.95 & & \\
\hline \multirow[t]{4}{*}{ FR } & Ethnic group (E) & 2 & 3.38 & 1.03 & .00 \\
\hline & Parents' Education (P) & 1 & 6.01 & 1.84 & .02 \\
\hline & $E \times P$ & 2 & 4.44 & 1.36 & .01 \\
\hline & Within group error & 45 & 3.27 & & \\
\hline \multirow[t]{4}{*}{ EP } & Ethnic group (E) & 2 & 18.98 & 2.12 & .04 \\
\hline & Parents' Education (P) & 1 & 11.09 & 1.24 & .00 \\
\hline & $E \times P$ & 2 & 3.34 & .37 & -.03 \\
\hline & Within group error & 45 & 8.98 & & \\
\hline
\end{tabular}

Note. $* p<.05 . \star \star 2<<.01$.

The categorical Parent's Education variable dichotomized participants on whether or not at least one of their parents completed an educational objective beyond high school. 
Table 12

Descriptives for Overall GPA, by Gender for Each Ethnic

Group

\begin{tabular}{llrr}
\hline Ethnic group & Gender & $\underline{M}$ & $\underline{S D}$ \\
\hline Caucasian & Male $(\underline{\underline{n}}=8)$ & 2.55 & .54 \\
& Female $(\underline{\underline{n}}=9)$ & 2.88 & .87 \\
& Entire group $(\underline{\underline{n}}=17)$ & 2.72 & .73
\end{tabular}

\begin{tabular}{llll} 
Mexican-American & Male $(\underline{\underline{n}}=6)$ & 2.39 & .50 \\
& Female $(\underline{\underline{n}}=11)$ & 2.28 & .69 \\
& Entire group $(\underline{\underline{n}}=17)$ & 2.32 & .62 \\
Vietnamese & Male $(\underline{\underline{n}}=6)$ & 3.18 & .86 \\
& Female $(\underline{\underline{n}}=11)$ & 2.73 & .55 \\
& Entire $g r o u p(\underline{\underline{n}}=17)$ & 2.89 & .69 \\
Entire sample & Male $(\underline{\underline{n}}=20)$ & 2.69 & .69 \\
& Female $(\underline{\underline{n}}=31)$ & 2.61 & .73 \\
& Entire $\operatorname{group}(\underline{\underline{N}}=51)$ & 2.64 & .71 \\
\hline
\end{tabular}


significantly different from that of participants in the Vietnamese $[\underline{E}(1,45)=.51, n$. s.] or the Mexican-American $[\underline{F}(1,45)=2.99$, n. s.] groups, while students in the Vietnamese group obtained a higher GPA than their peers in

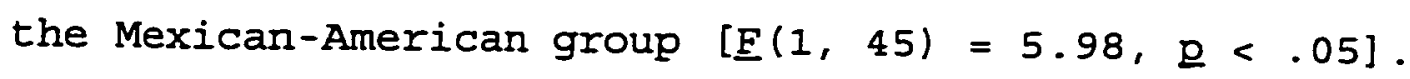

Means and standard deviations were computed for GPA, by ethnic group and parents' education classification (as shown in Table 13). An ANOVA was carried out to determine whether participants' overall GPA varied significantly depending on whether they had at least one parent who had completed an educational objective beyond high school. This analysis revealed that parents' education classification had no impact on variance of $\operatorname{GPA}[\underline{E}(1,45)=2.78, \mathrm{n.s.}]$ and did not interact with GPA variance attributable to ethnic group membership $[\underline{E}(2,45)=2.26$, n.s. $]$.

Summary of Exploratory Analyses

These exploratory analyses revealed significant differences between the scores obtained by participants in the three ethnic groups on all ssHA scales. Participants in the Caucasian group scored consistently higher than their counterparts in the Vietnamese group on all SSHA scales, while students in the Mexican-American group obtained scores similar to those of participants in the caucasian group in two scales (TA and EA) and similar to those of their peers in the Vietnamese group in the remaining scales (DA and WM). 
Table 13

Descriptives for Overall GPA, by Parents' Education

Classification for Each Ethnic Group

\begin{tabular}{|c|c|c|c|c|c|c|}
\hline & \multicolumn{6}{|c|}{ Group } \\
\hline & \multicolumn{2}{|c|}{ Caucasian } & \multicolumn{2}{|c|}{ Mexican-American } & \multicolumn{2}{|c|}{ Vietnamese } \\
\hline & HIGH & LOW & HIGH & LOW & HIGH & LOW \\
\hline & $(\underline{n}=15)$ & $\underline{n}=21$ & $(\underline{n}=6)$ & $(\underline{\underline{n}}=11)$ & $(\underline{n}=5)$ & $(\underline{n}=12)$ \\
\hline$\underline{\mathbf{M}}$ & 2.60 & 3.61 & 2.47 & 2.23 & 2.62 & 3.00 \\
\hline$\underline{S D}$ & .69 & .16 & .42 & .71 & 1.01 & .52 \\
\hline
\end{tabular}


These findings could suggest that students of different ethnic groups endorse differently the study practices and behaviors measured by the SSHA. These differences could be attributable, for example, to possible ethnic variations in upbringing and social norms, since different cultural standards may promote placing dissimilar emphasis on different values and behaviors. Hence, students in the Vietnamese group, for instance, could be less concerned with the area measured by the TA scale than students in the Caucasian group, consequently subscribing less to those behaviors and scoring lower on that scale.

The results of ANOVAs on the ILP scales showed ethnic group differences only in DP. This could mean either that participants in the three groups are not different in some of the specific learning processes they engage in, or that the ILP instrument is not as sensitive as the SSHA in detecting differences that might exist between ethnic groups. When ANOVAs were carried out to assess variance in academic performance between the ethnic groups, only one significant group difference was found. Students in the Vietnamese group obtained a higher GPA than those in the Mexican-American group.

\section{Conclusions}

This study investigated the learning styles and study behaviors that are most correlated to academic success of 
different ethnic groups in higher education settings, by assessing the relationships between ILP and SSHA scores, and overall GPAs of Caucasian, Mexican-American, and Vietnamese college students.

Analyses revealed significant correlations between SSHA and ILP scales and GPA, but only for participants in the Caucasian group. This finding suggests that participants in the Vietnamese and Mexican-American groups may benefit most from study methods and learning processes that have underlying structures not measured by the SSHA and ILP scales. This difference in the GPA-predictive ability of the SSHA and ILP scales is most clearly illustrated by the data obtained from students in the Vietnamese group, who scored significantly lower than their peers in the caucasian group in all SSHA scales, yet obtained a higher (although not significantly different) overall GPA.

This study is not able to clearly discern SSHA and ILP differences attributable strictly to ethnic background from differences originating in SES variables in which the groups are unequal (e.g., family of origin's yearly income), due in part to the small sample size. However, differences in SES did not seem to correspond to differences in academic performance. While differences in SES were most apparent between participants in the Caucasian group and their counterparts in the Vietnamese and Mexican-American groups, 
the former did not obtain significantly different GPAs than the latter. It might have been expected, for example, that participants in the Caucasian group would have benefited from additional guidance from their parents, who were more likely to have succeeded in college and thus may have been better prepared to instruct their children on the appropriate implementation of behaviors conducive to academic success. However, participants in the Caucasian group did not obtain a significantly higher GPA than their peers in the Mexican-American and the Vietnamese groups. The presence of differences in predictability of GPA, whether attributable to ethnicity, SES, or other factors, invites further research to locate and address this inequality. Such research should target larger samples from different ethnic groups, so that thorough comparisons are possible between and within ethnic and SES categories. Those findings would contribute to better conceptualize variables related to the academic success of ethnic minority students, in order to develop educational programs that more accurately address the strengths and weaknesses of different groups.

Ethnic differences in academic attainment are tied to a variety of factors, which requires that steps are taken in separate areas in order to address the sources and reduce the magnitude of these differences. Current trends in these 
areas suggest an uncertain forecast. While affirmative action programs have been credited for the modest increase in the number of minority students enrolling in higher education programs in the last few years (Wilson, 1995), recent changes in the political arena make for a discouraging outlook. For example, in November of 1997, the U.S. Supreme Court upheld a measure passed by voters in California to end race-preference practices in higher education admissions.

In contrast with the likely counterproductive results of these political changes, new educational programs have successfully implemented practical solutions that contribute to a more optimistic projection of the educational development of ethnic minority stidents. For example, the "Equity 2000" Program increases minorities' achievement in math and science, which are subjects typically used as filters for college entrance and have been shown as particular weaknesses in the backgrounds of African-American and Hispanic high school students (Murray, 1997).

Related research should focus on the development of school admissions' selection tools that are economic enough to be appealing for use by admissions officers, yet sound and thorough enough to be equally useful to predict the academic promise and success of students from a broad spectrum of ethnic and SES backgrounds. Relating to this 
issue, it is also important that professionals making predictions based on standardized tests maintain a supportable conceptual understanding of what those tests do and do not measure, especially if this study's results are a reflection of the psychometric properties of other tests utilized to measure academic promise. For example, recent research indicates that Graduate Record Examination (GRE) scores are somewhat useful for predicting GPA but not for predicting other important areas of academic performance such as those gauged by professors' ratings of students' analytical, research, and teaching abilities (sternberg \& Williams, 1997).

This study should be considered only exploratory, given the concerns with the statistical properties of SES data and the small sample size. However, its results suggest that ethnic differences reported in children's learning styles (e.g., Dunn \& Griggs, 1990) may be carried onto adulthood, and in light of current trends in the political climate, it is very important for educational organizations to ensure that the measurement tools and delivery methods they employ are not unequally fruitful for students of different ethnic groups. The findings from this investigation reinforce the call for additional research to expand the body of knowledge in this area. 
References

American Psychological Association. (1992). Ethical principles of psychologists and code of conduct. American Psychologist, 47, 1597-1611.

Bliss, L. B., \& Mueller, R. J. (1993). An instrument for the assessment of study behaviors of college students. Reading Research and Instruction, 32(4), 46-52.

Brown, W. F., \& Holtzman, W. H. (1965). Survey of Study Habits and Attitudes Manual. New York: American Psychological Corporation.

Cone, A. A., \& Owens, S. K. (1991). Academic and locus of control enhancement in a freshman study skills and college adjustment course. Psychological Reports, 68 (3, Pt 2), 1211-1217.

Dunn, R., \& Griggs, S. A. (1990). Research on the learning style characteristics of selected racial and ethnic groups. Reading, Writing, and Learning Disabilities, 6 (3), $261-280$.

Hair, J. F., Jr., Anderson, R. E., Tatham, R. L., \& Black, W. C. (1995). Multivariate data analysis (4th ed.). New Jersey: Prentice-Hall, Inc.

Halpern, D. F. (1997). Sex differences in intelligence. American Psychologist, 52 (10), 1091-1102.

Howell, D. C. (1989). Eundamental statistics for the Behavioral Sciences (2nd ed.). Boston, Massachusetts: PwSKENT Publishing Company. 
Kleinbaum, D. G., \& Kupper, L. L. (1978). Applied regression analysis and other multivariable methods. North Scituate, Massachusetts: Duxbury Press.

Murray, B. (1997, September). "Equity 2000" gives boost to ethnic-minority students. APA Monitor, p. 40.

National Advisory Mental Health Council (1996). Basic behavioral science research for mental health: Sociocultural and environmental processes. American Psychologist, 51(7), $722-731$.

Nettles, M. T. (1990). Success in doctoral programs: Experiences of minority and white students. American Journal of Education, 98 (4) 494-522.

Nist, S. L., Simpson, M. L., Olejnik, S., \& Mealey, D. L. (1991). The relation between self-selected study processes and test performance. American Educational Research Journal, $28(4), 849-874$.

Norusis, M. J. (1992). SPSS/PC+ Base System User's Guide, Version 5.0. Chicago: SPSS, Inc.

Phenice, L. A., \& Griffore, R. (1994). College students' stereotypes. College Student Journal, 28 (3), 373375 .

Poodry, C. (1996). Rethinking approaches to affirmative action. In Malcom, S. M., George, Y. S., \& Van Horne, V. V. (Eds.), Proceedings of the American Association for the Advancement of Science Workshop on the Effect of the 
Changing Policy Climate on Science, Mathematics, and Engineering Diversity (pp. 1-11). American Association for the Advancement of Science, Washington, DC.

Schmeck, R. R. (1983). Learning styles of college students. In R. Dillon \& R. Schmeck (Eds.), Individual differences in cognition, Vol. I (pp. 233-279). New York: Academic Press.

Schneider, S. F. (1996). Random thoughts on leaving the Eray. American Psychologist, 51(7), 715-721.

Steele, C. M. (1997). A threat in the air. American Psychologist, 52(6), 613-629.

Sternberg, J. R., \& Williams, W. M. (1997). Does the Graduate Record Examination predict meaningful success in the graduate training of psychologists? American Psychologist, $52(6), 630-641$.

Suzuki, L. A., \& Valencia, R. R. (1997). Race-ethnicity and measured intelligence. American Psychologist, 52 (10), $1103-1114$.

Turner, G. Y. (1992). College student's self-awareness of study behaviors. College student Journal, 26 (1), 129-134.

U.S. Employment Service (1991). Dictionary of Occupational Titles (4th ed.). The Administration: Supt. of Docs., U.S. G.P.O., distributor. Washington, DC.

Wilson, R. (1995). Affirmative Action: Yesterday, today, and beyond. American Council on Education. Washington, DC. 
Appendix A

Approval of Thesis Proposal and Use of Human Subjects

ETHNIC DIFFERENCES IN LEARNING STYLES AND

STUDY METHODS OF COLLEGE STUDENTS

\author{
A Thesis Proposal \\ Presented to \\ the Faculty of the Department of Psychology \\ San Jose State University
}

In Partial Fulfillment

of the Requirements for the Degree

Master of Arts

by

Sergio S. Queirolo

December 4, 1996 


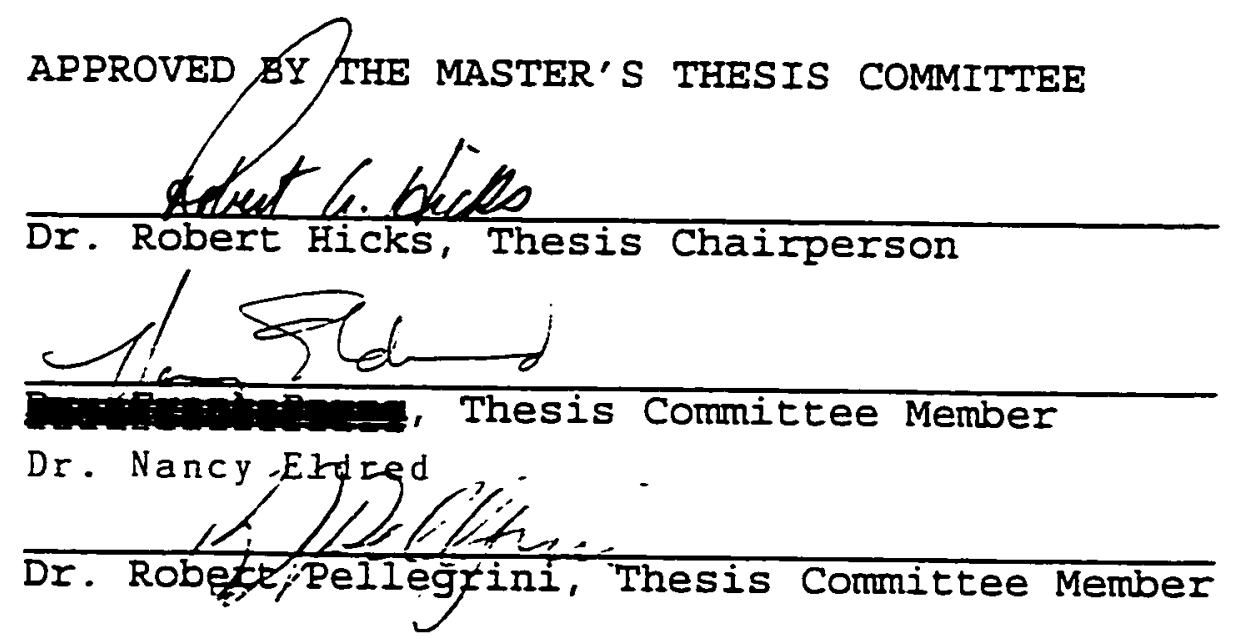


TO: $\quad$ Sergio S. Queirolo

96 S. 6th St., Apt. \#3

San Jose, CA 95112-3559

FROM :

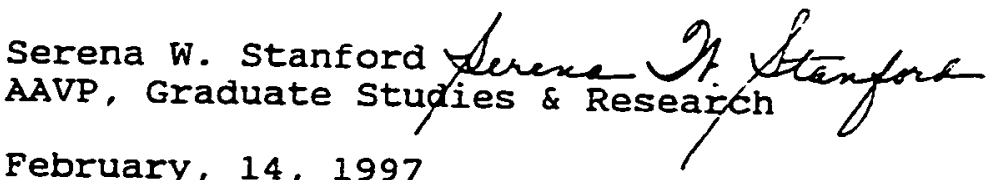

DATE :

$$
\text { February, 14, } 1997
$$

The Human Subjects-Institutional Review Board has approved your request to use human subjects in the study entitled:

$$
\begin{aligned}
& \text { "Ethnic Differences in Learning Styles and Study } \\
& \text { Methods of College Students" }
\end{aligned}
$$

This approval is contingent upon the subjects participating in your research project being appropriately protected from risk. This includes the protection of the anonymity of the subjects' identity when they participate in your research project, and with regard to any and all data that may be collected from the subjects. The Board's approval includes continued monitoring of your research by the Board to assure that the subjects are being adequately and properly protected from such risks. If at any time a subject becomes injured or complains of injury, you must notify serena Stanford, Ph.D., immediately. Injury includes but is not limited to bodily harm, psychological trauma and release of potentially

Please also be advised that all subjects need to be fully informed and aware that their participation in your research project is voluntary, and that he or she may withdraw from the project at any time. Further, a subject's participation, refusal to participate, or withdrawal will not affect any services the subject is receiving or will receive at the institution in which the research is being
conducted.

If you have any questions, please contact me at (408) 924-2480. 
Appendix B

Sample Contact Letter

Dear <student organization's contact names:

I got your name from the student Activities office directory at SJSU, as the contact person for the <student organizations. I am a Graduate student at the Psychology Department, and I would like to ask the members of the <student organizations to be participants in the research I'm doing for my Thesis.

I would like to invite you to contribute to an investigation of factors that may affect the academic success of college students with different ethnic backgrounds. Participation entails completing questionnaires (which take up to 45 minutes to fill out) that gather data on study habits, socio-demographic variables, learning styles, and semester and overall Grade Point Averages. You will have up to three weeks to complete and return the surveys to me, and all data will be kept strictly confidential.

I am unable to provide any compensation for your valuable participation (I'm just as poor as every other student!), but those enrolled in a Psychology 001 course would receive a 1 -hour credit toward their experiment participation requirement (unless they have already participated in this study, which is study Number 597-008). 
I cannot graduate until I collect enough data for this study, so I will be very grateful for your participation! To be eligible to participate, a student must be a freshman or sophomore, 18 years of age or older, and whose parents are both African-American, or both Asian or AsianAmerican, or both Caucasian, or both Mexican or MexicanAmerican.

If any students in your organization are interested in participating, please ask them to sign up on the attached sheet. You can then return the list to me via inter-campus mail to: Sergio Queirolo, Psychology Department, DMH 157, Extended Zip 0120; or you can call me at <author's home phones and let me know where I can pick it up.

A few days after I receive the sign-up sheet I will forward the questionnaires to you. If after reviewing the questionnaires students decide not to participate, they can return the blank questionnaires to me without any obligation whatsoever.

Please call me at <author's home phone> if you would like more information about my study. Thank you, and best wishes on your academic endeavors at SJSU.

Sincerely,

Sergio Queirolo 
Research Participation Sign-up Sheet (study s97-008) <student organizations

\section{PLEASE PRINT CLEARLY}

Name (Last, First)

Enrolled in Psychology 001?
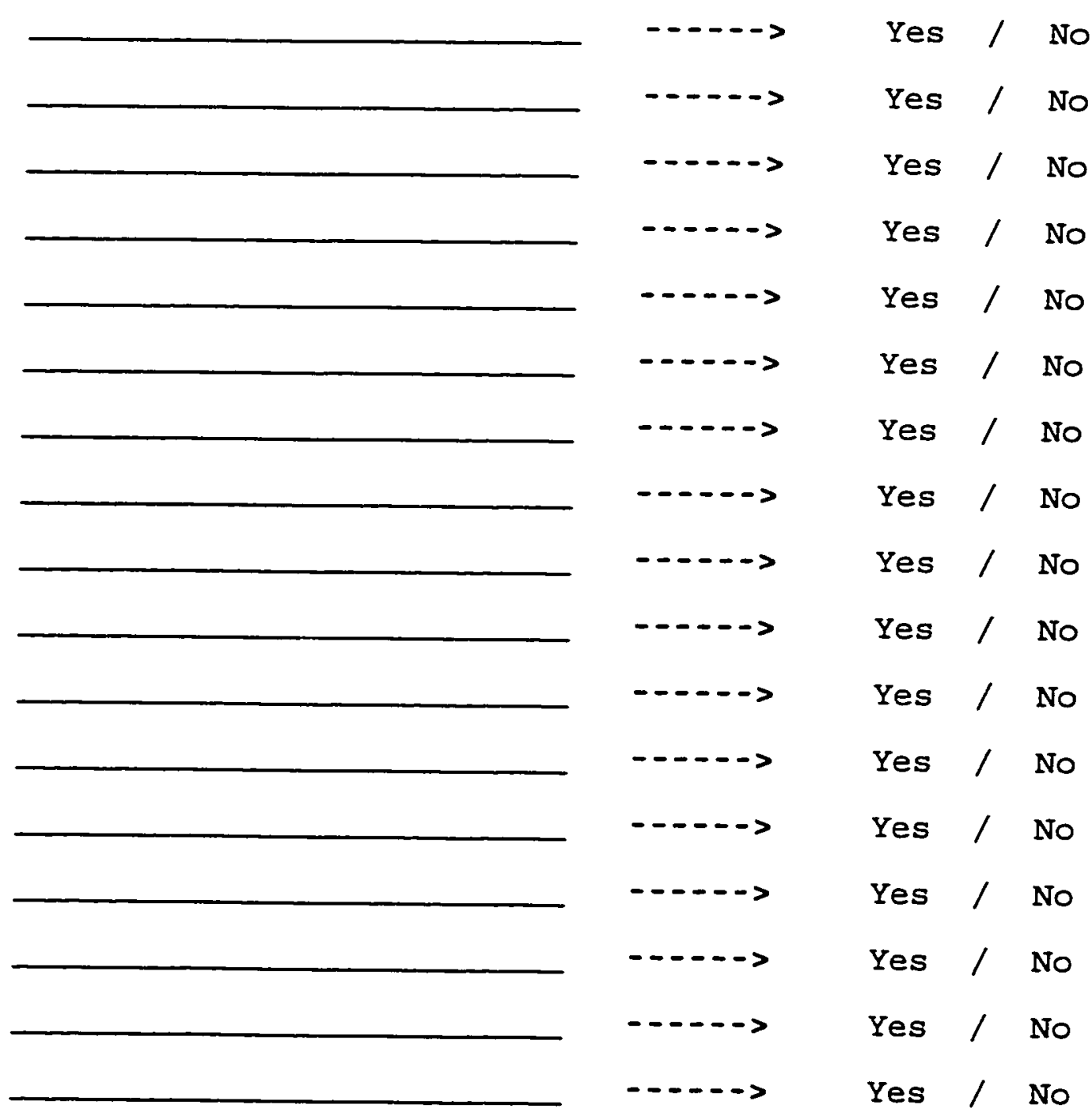

Please return to:

Sergio Queirolo - Psychology Department

DMH 157 Extended Zip: 0120

or call <author's home phones to arrange for pick-up. 
Appendix C

Sample Research Sign-up sheet

RESEARCH CREDIT: One hour.

DESCRIPTION :

This is an investigation of factors that may affect the academic success of lower division college students. Participation entails completing questionnaires (which take approximately 45 minutes to fill out) that gather data on study habits, socio-demographic variables, learning styles, and semester and overall Grade Point Averages. Participants will receive the questionnaires and will have up to three weeks to complete and return the surveys to the investigator. Your participation will be greatly appreciated!!!

REQUIREMENTS :

* You must be a Freshman or Sophomore,

AND

* You and both of your parents must be either:

African or African-American

OR

Asian or Asian-American

OR

Caucasian

OR

Mexican or Mexican-American. 
TO SIGN UP, print your name and phone number below so you can get more information, and to make arrangements to receive the questionnaires should you choose to participate.

\section{PLEASE PRINT CLEARIY}

Name

Phone Number (s)

Best times to reach you 
Appendix D

Background Questionnaire

PLEASE PRINT ALL ANSWERS TO THE QUESTIONS BELOW

1. What is your date of birth? $(\mathrm{mm} / \mathrm{dd} / \mathrm{yy})$ :

2. What is your gender? (circle one): Male Female

3. What is your Ethnic Background? (circle one):

African-American Asian-American

Caucasian Mexican-American

4. Were you born in the United States? (circle one): Yes No 4b. If "No", how old were you when you moved to the U.S.? 4c. If "No", in what country were you born?

5. Is English your first language? (circle one): Yes No 5b. If "No", what is your first language?

6 . What was your father's country of birth?

7. What was your mother's country of birth?

8. What is your major at SJsU?

9. Including this semester, how many semesters of college have you attended (including all colleges attended)?

10. How many units are you taking this semester?

11. How many units do you typically take each semester?

12. What is your class level? (circle one):

Freshman Sophomore Junior Senior Graduate

13. What is your High School GPA?

14. What is the yearly income of your family of origin (parents or guardians)? \$ 
15. What is the highest level of education completed by your father?

16. What is the highest level of education completed by your mother?

17. What is your Eather's occupation?

18. What is your mother's occupation?

19. Do you have any brothers or sisters? (circle one) Yes No 19b. If "Yes", please indicate the gender and list the age and highest level of education achieved by each brother or sister:

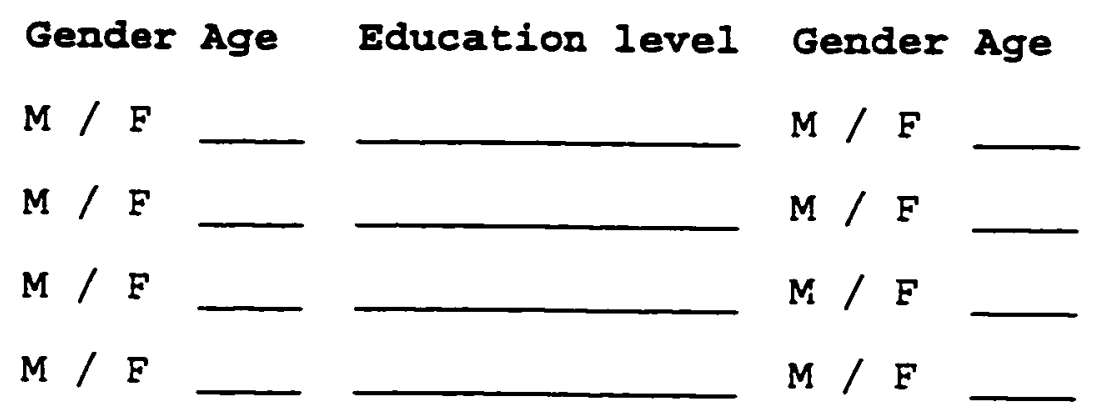

20. Indicate your marital status (check one):

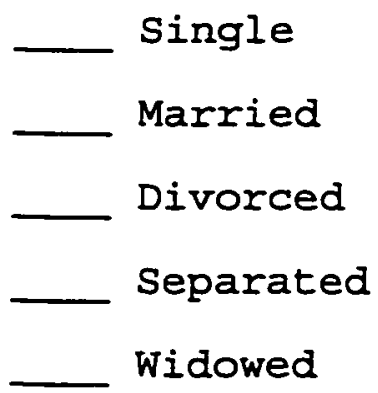

21. Describe your primary residence while attending school (check one):

On-campus dorm or apartment Off-campus house 
- Off-campus apartment

Family of origin's (parents or guardians) home __ Fraternity/Sorority

22. Describe your living arrangements (check one):

Alone

With spouse/partner

With friends/roommates (how many?

With family members (how many? ___ )

23. Including relatives and roommates, how many people do you live with?

24. What is your personal yearly income? (if you have a spouse/partner, include his/her income) $\$$

25. During the semester, how many hours do you work in a typical week?

26. During the semester, how many days do you work in a typical week?

27. What is your usual or typical work shift? (check one): Days

Evenings

Graveyard

other (explain: 
Appendix $E$

Grade Point Average (GPA) Release Form

By signing this GPA Release Form, I authorize the principal investigator (Sergio Queirolo) to access my official spring 1997 semester and overall GPAs from SJSU's office of Admissions and Records.

PLEASE PRINT CLEARLY!

Date :

Name (Please print):

Social Security Number:

Signature: 
Appendix $F$

Informed Consent Form

AGREEMENT TO PARTICIPATE IN RESEARCH AT SAN JOSE STATE UNIVERSITY

Responsible investigator: Sergio S. Queirolo, B.A.

Faculty supervisor: Dr. Robert Hicks, Psychology Professor

I have been invited to participate in research on the relationship between demographic variables (e.g., ethnic background), individual differences (e.g., learning styles), and Grade Point Average (GPA). If I decide to participate, I will be asked to complete three questionnaires that will take approximately 45 minutes to fill out, and to sign a release form authorizing the investigator to access my official Spring 1997 semester and overall GPA from the University's Admissions and Records office. If I am enrolled in a Psychology 001 class, I will receive a 1 -hour credit toward my Experiment Participation requirement if I complete every questionnaire item and sign the GPA release form.

There are no known risks for participating in this study. Possible benefits of participating in this project include contribution to knowledge concerning academic achievement in college students.

To protect confidentiality, data gathered from this study will be stored in a file drawer which no one but the experimenter will be able to access. If the results of this 
study are published, no personally identifiable information will be disclosed.

I understand that my participation in the study is voluntary. My decision to participate or not participate will not in any way prejudice my future relations with san Jose State University. If I decide to participate, I am free to withdraw my consent and to discontinue my participation at any time without penalty.

I will be given the opportunity to ask questions prior to the start of the study. If I have questions after my participation has ended, I may contact sergio Queirolo through the Psychology Department (DMH 157). If I have any complaints about the procedure, I may contact Dr. Robert Cooper, Psychology Department Chair, at 924-5600 (DMH 157). For questions about research participants' rights, or in the event of research-related injury, I may contact Dr. Serena Stanford (Associate Academic Vice President for Graduate Studies) at 924-2480.

I am making a decision whether or not to participate. My signature below indicates that I have decided to participate having read the information provided above. I have received a copy of this consent form for my records. DATE Participant \#

\section{SIGNATURE}


SOCIAL SECURITY \#

SIGNATURE (Investigator) 
Appendix G

Verification of Statistical Assumptions and Analyses of Socio-Economic Data

Prior to executing analyses to determine the significance of any group differences in SSHA, ILP, and GPA, the data was inspected for the presence of outliers arising from procedural error or not representing a valid observation in the population, as suggested by Hair, Anderson, Tatham, and Black (1995), and none were detected. The normality and homoscedasticity of SSHA, ILP, and GPA, were also investigated to ensure that the main requirements for ANOVA analyses were met. As can be seen in Table Gl, variance of SSHA, ILP, and GPA is not significantly different across the three ethnic groups. The results of tests of normality for each scale and GPA, summarized in Table G2, reveal that the DA and FR scales fail to meet the normal distribution that is assumed in ANOVA analyses. Although there are methods to correct for violations of normality, such data transformations in turn may change the interpretation of the variables (Hair et al.), hence no corrective data transformations were executed.

In addition to verifying the main assumptions for ANOVA analyses, demographic variables were examined, to reduce the likelihood that possible group differences on SSHA, ILP, or GPA, originate from confounding SES variables, and to 
Table GI

Tests of Homoscedasticity Across Ethnic Groups for Overall GPA and ILP and SSHA Scales

\begin{tabular}{|c|c|c|c|c|}
\hline \multirow[b]{2}{*}{ Variable } & \multicolumn{4}{|l|}{ Levene } \\
\hline & statistic & $\underline{\text { dfI }}$ & $\underline{\mathrm{df2}}$ & $\underline{p}$ \\
\hline Deep Processing & .810 & 2 & 48 & .451 \\
\hline Methodical study & .387 & 2 & 48 & .681 \\
\hline Fact Retention & .204 & 2 & 48 & .816 \\
\hline Elaborative Processing & .482 & 2 & 48 & .620 \\
\hline Delay Avoidance & 3.014 & 2 & 48 & .059 \\
\hline Work Methods & .447 & 2 & 48 & .642 \\
\hline Teacher Approval & 1.584 & 2 & 48 & .216 \\
\hline Education Acceptance & .064 & 2 & 48 & .939 \\
\hline Overall GPA & .483 & 2 & 48 & .620 \\
\hline
\end{tabular}


Table G2

Kolmogorov-Smirnov (Lilliefors) Normality Tests for overall GPA and ILP and SSHA Scales

\begin{tabular}{lccc}
\hline Variable & $\underline{D}$ & $\underline{\text { df }}$ & $\underline{D}$ \\
\hline Deep Processing & .103 & 51 & .200 \\
Methodical study & .119 & 51 & .071 \\
Fact Retention & .127 & 51 & .038 * \\
Elaborative Processing & .077 & 51 & .200 \\
Delay Avoidance & .151 & 51 & $.005 *$ \\
Work Methods & .114 & 51 & .098 \\
Teacher Approval & .078 & 51 & .200 \\
Education Acceptance & .084 & 51 & .200 \\
Overall GPA & .071 & 51 & .200 \\
\hline Note. * A small level of significance indicates that the \\
null hypothesis of normality should be rejected.
\end{tabular}


describe in more detail the ethnic groups being studied. For this purpose, parental employment, parental income, parental education level, personal income and work-hours, gender, and marital status were selected for evaluation.

The occupations of participants' parents were categorized and tallied for each group. As can be seen in Table G3, most parents of participants in the Caucasian group held managerial, technical, or professional occupations, with most of the remaining parents in that group holding clerical and sales occupations. On the other hand, parents of participants in the Mexican-American and Vietnamese groups were distributed more broadly across all the occupational classifications, suggesting that the Caucasian group is more homogeneous on this variable than the other two groups. Visual inspection of this data suggests that parents of participants in the caucasian group cluster around the occupations that intuitively denote a higher economic standing. However, the expected frequency of cases for each cell in an occupation-by-ethnic-group matrix is too small to carry out a chi-square analysis to measure the degree of independence of these two variables.

Visual examination of the participants' family of origin's income data, presented in Table G4, further suggests that the three ethnic groups differ in terms of their parents' yearly income. A chi-square analysis 
Table G3

Number of Parents in Each Occupational Classification, for the Entire Sample and for Each Ethnic Group

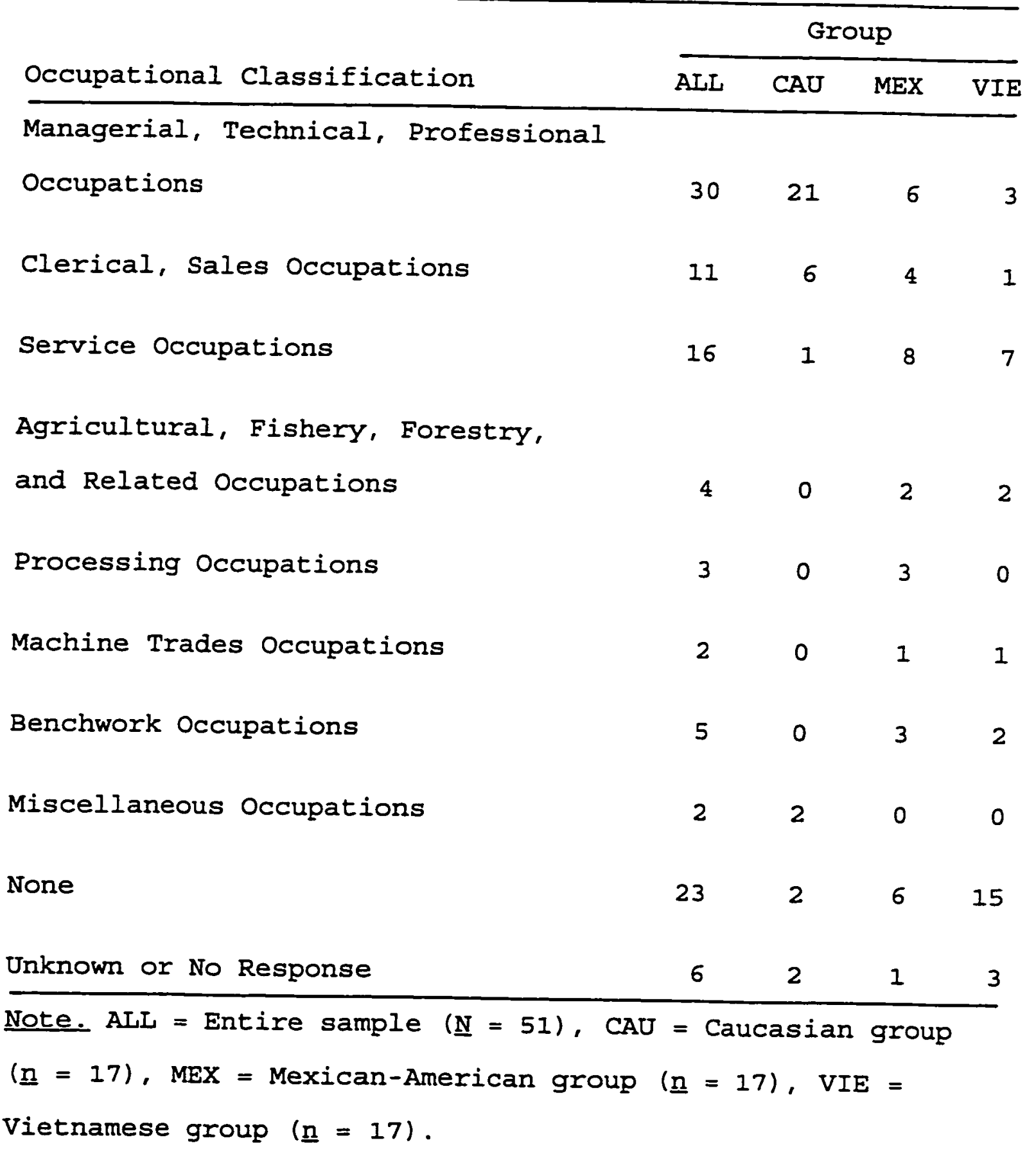


Table G4

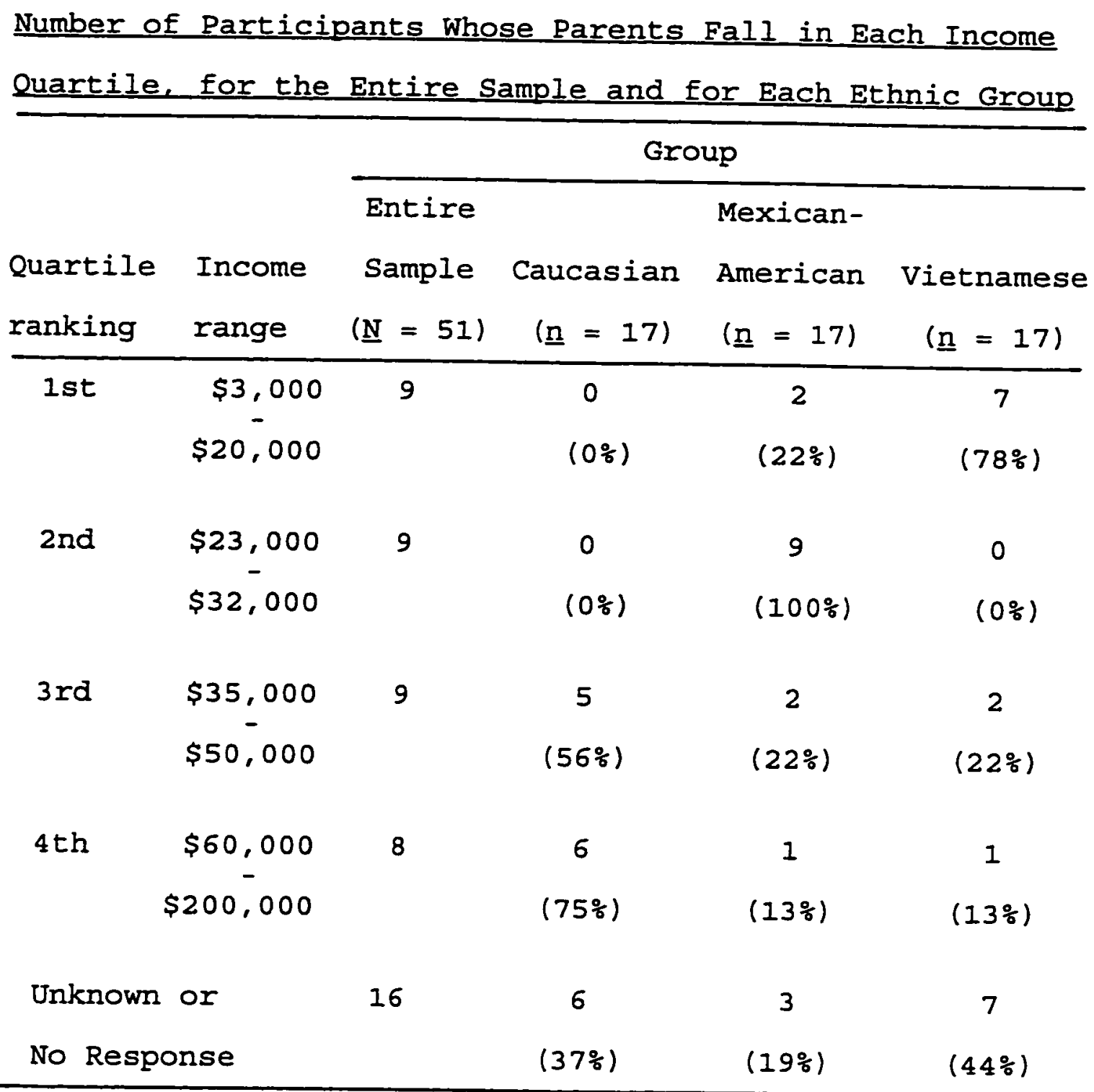

Note. Values in parentheses indicate the approximate percentage of cases for each ethnic group within each quartile. 
confirms that the distribution of cases across the parental income categories is not independent of the ethnic group category $\left[\underline{\chi^{2}}(6)=34.24, \underline{\underline{p}}<.01\right]$. Complementing the apparent group differences in parental employment, this data indicates that those participants in the caucasian group originate from households that fall exclusively in the two higher quartile income classifications, with a mean income of $\$ 77,636(\underline{S D}=53,718)$, while participants in both the Mexican-American and Vietnamese groups originate from families that seem more spread out over the four quartiles, with a higher concentration in the lowest two quartiles, as reflected by their mean family income of $\$ 32,857$ ( $\underline{S D}=$ $16,328)$ and $\$ 24,500(\underline{S D}=28,794)$ respectively. The large standard deviations indicate a considerable degree of variability within each group.

These differences in the parents' occupational and income classifications could be explained by the parents' highest level of education completed. As can be seen in Table G5, a great majority of parents of Caucasian participants had a level of education higher than high school, while most of the parents of Mexican-American and Vietnamese participants had an educarion level of high school or less. After collapsing the six original educational categories into two, based on whether the parents' highest level of education was either beyond 
Table G5

Number of Parents at Different Education Levels, for the Entire Sample and for Each Ethnic Group

Highest level of

Education Completed

College

Trade School or Some college

High School

Middle School

Elementary School

None

Note. ALI = Entire sample $(\underline{N}=51)$ $(\underline{n}=17), \operatorname{MEX}=$ Mexican-American group $(\underline{\underline{n}}=17), \mathrm{VIE}=$ Vietnamese group ( $\underline{n}=17$ ).

\begin{tabular}{cccr}
\multicolumn{4}{c}{ Group } \\
\hline ALL & CAU & MEX & VIE \\
\hline 37 & 23 & 9 & 5
\end{tabular}

4

2

0

24

7

6

8

2

5

26

0

14

3

0

0

, CAU = Caucasian group

2

11

1

12 3 
high school or not, a chi-square confirmed that this categorization of the participants' parents' education level was not independent of ethnic group for either the participants' fathers $\left[\underline{\chi^{2}}(2)=11.02, \underline{\underline{p}}<.01\right]$ or mothers $\left[\underline{\chi^{2}}(2)=15.06, \underline{p}<.01\right]$.

Ethnic group differences in participants' gender, marital status, employment, and yearly income were also evaluated. A Chi-square indicated that gender and ethnicity were independent of each other $\left[\underline{\chi^{2}}(2)=.653, \underline{\mathrm{p}}=.72\right]$. Additionally, most participants were single, except for one male in the Mexican-American group, and one male and one female in the Caucasian group, so it appears that marital status and gender are not a likely source of substantial confounding between the groups. However, participants' placement in each yearly income quartile classification, as shown in table G6, was not independent of the ethnic group category $\left[\underline{\chi}^{2}(6)=16.50, \underline{D}<.02\right]$. These group differences in mean personal yearly income are plausibly the result of corresponding differences in the average number of hours worked per week (as summarized in Table G7).

While it is apparent that the three ethnic groups are different on some of the measures of SES just discussed, the statistical properties of these data make it difficult to determine what impact, if any, these variables have on participants' SSHA, ILP, and GPA, given the relatively small 
Table G6

Number of Participants in Each Personal Income Quartile,

for the Entire Sample and for Each Ethnic Group

\begin{tabular}{|c|c|c|c|c|c|}
\hline \multirow{3}{*}{$\begin{array}{l}\text { Quartile } \\
\text { ranking }\end{array}$} & \multirow{3}{*}{$\begin{array}{l}\text { Income } \\
\text { range }\end{array}$} & \multicolumn{4}{|c|}{ Group } \\
\hline & & $\begin{array}{l}\text { Entire } \\
\text { Sample }\end{array}$ & Caucasian & $\begin{array}{l}\text { Mexican- } \\
\text { American }\end{array}$ & \multirow{2}{*}{$\begin{array}{l}\text { Vietnamese } \\
\qquad \underline{\underline{n}}=17)\end{array}$} \\
\hline & & $(\underline{N}=51)$ & $(\underline{n}=17)$ & $(\underline{n}=17)$ & \\
\hline 1st & $\begin{array}{c}\$ 0 \\
- \\
\$ 1,500\end{array}$ & 12 & $\begin{array}{c}3 \\
(25 \%)\end{array}$ & $\begin{array}{c}6 \\
(50 \%)\end{array}$ & $\begin{array}{c}3 \\
(25 \%)\end{array}$ \\
\hline $2 n d$ & $\begin{array}{c}\$ 2,000 \\
- \\
\$ 4,500\end{array}$ & 12 & $\begin{array}{c}2 \\
(17 \circ)\end{array}$ & $\begin{array}{c}1 \\
(8 \div)\end{array}$ & $\begin{array}{c}9 \\
(75 \%)\end{array}$ \\
\hline $3 r d$ & $\begin{array}{l}\$ 5,000 \\
- \\
\$ 8,000\end{array}$ & 12 & $\begin{array}{c}4 \\
(33 \%)\end{array}$ & $\begin{array}{c}6 \\
(50 \%)\end{array}$ & $\begin{array}{c}2 \\
(17 \%)\end{array}$ \\
\hline $4 t h$ & $\begin{array}{c}\$ 10,000 \\
- \\
\$ 79,000\end{array}$ & 12 & $\begin{array}{c}7 \\
(58 \%)\end{array}$ & $\begin{array}{c}3 \\
(25 \%)\end{array}$ & $\begin{array}{c}2 \\
(17 \%)\end{array}$ \\
\hline \multicolumn{2}{|c|}{ No response } & 3 & $\begin{array}{c}1 \\
(33 \div)\end{array}$ & $\begin{array}{c}1 \\
(33 \%)\end{array}$ & $\begin{array}{c}1 \\
(33 \%)\end{array}$ \\
\hline
\end{tabular}

Note. Values in parentheses indicate the approximate percentage of cases for each ethnic group within each quartile. 
Table G7

Descriptives for Participants' Typical Number of Hours

Worked Weekly and Personal Yearly Income, by Ethnic Group

\begin{tabular}{|c|c|c|c|c|c|c|}
\hline \multirow[b]{2}{*}{ Group } & \multirow{2}{*}{$\frac{\text { Hours }}{\underline{M}}$} & \multicolumn{2}{|c|}{ worked weekly } & \multicolumn{3}{|c|}{ Personal yearly income } \\
\hline & & $\underline{\text { Mdn }}$ & $\underline{\mathrm{SD}}$ & $\underline{M}$ & Mdn & $\underline{\mathrm{SD}}$ \\
\hline CAU & 21.0 & 21.5 & 18.3 & 16,725 & 8,000 & 23,018 \\
\hline MEX & 13.1 & 15.0 & 9.3 & 8,775 & 5,500 & 15,733 \\
\hline VIE & 11.9 & 15.0 & 11.1 & 4,138 & 4,000 & 3,147 \\
\hline
\end{tabular}

Note. $\mathrm{CAU}=$ Caucasian group $(\underline{\underline{n}}=16)$, MEX = Mexican-American group $(\underline{\underline{n}}=16), \mathrm{VIE}=$ Vietnamese group $(\underline{\underline{n}}=16)$. 
sample sizes, very unequal cell sizes for occupational and educational categories, and the non-normal distribution of both the family of origin's and the personal yearly incomes, as reflected by their respective Lilliefors statistic of the Kolmogorov-Smirnov test $[\underline{D}(35)=.239, \underline{D}<.01$, and $\underline{D}(48)=$ $.295, \underline{D}<.01]$. Consequently, these SES differences pose as a potential confound during inferential analyses of group differences on GPA, SSHA and ILP.

Although the standard ANOVA procedure requires that all cell frequencies be equal (Norusis, 1992), there is a technique which yields valid ANOVA results as long as there are no empty cells and no cell has more than twice the number of cases of any other cell (Kleinbaum \& Kupper, 1978). Using this procedure, the results of spss analyses could be double-checked for validity, making it safe to include ethnicity and gender as independent variables in ANOVA analyses, to measure their contribution to variance of GPA, SSHA, and ILP.

As noted above, the statistical properties of participants' parents' educational data impede any straightforward analyses of the impact it might have on the relationships between ethnicity, SSHA and ILP scores, and GPA, given the relatively small sample sizes and the very unequal cell sizes. However, it was deemed necessary to attempt to measure the influence of level of education 
attained by participants' parents, given its likely impact on the participants' academic undertakings as suggested by existing research (e.g., Suzuki \& Valencia, 1997).

Consequently, a dichotomous variable was created to classify students on whether or not at least one of their parents had attained an educational level beyond high school.

This dichotomy resulted in a classification that violates one of the requirements for using the ANOVA technique described by Kleinbaum and Kupper (1978), because some cells ended up with more than twice the number of cases of another cell. While 15 participants in the Caucasian group reported that at least one of their parents had obtained an education beyond high school, only 6 students in the Mexican-American group and 5 in the Vietnamese group made a similar report. Thus, although the results of standard ANOVAs were double-checked using this procedure, it is important to keep in mind that these analyses should be interpreted cautiously and only as an approximation. 

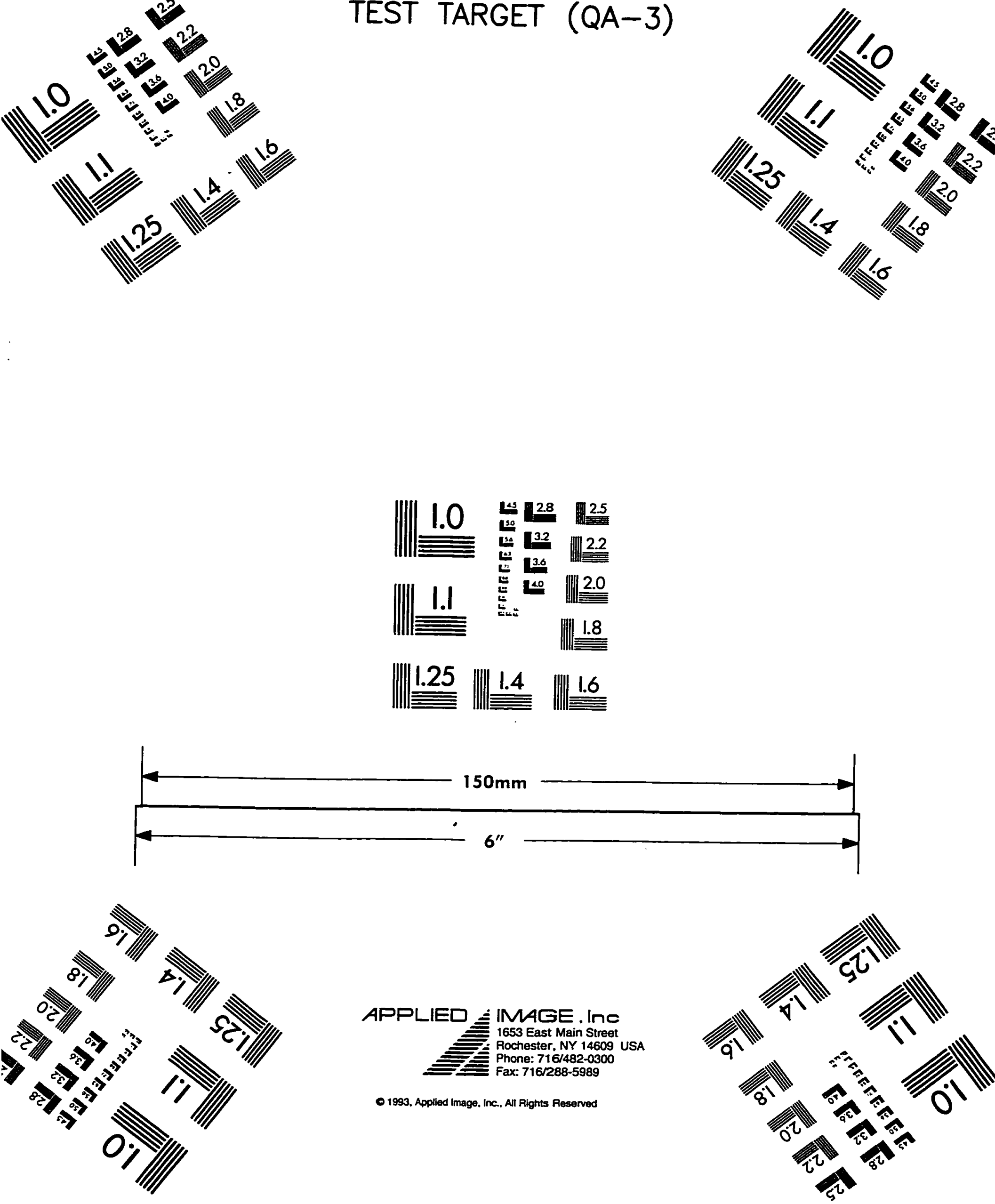